UNIVERSIDADE DE BRASÍLIA

FACULDADE DE AGRONOMIA E MEDICINA VETERINÁRIA

PROGRAMA DE PÓS-GRADUAÇÃO EM AGRONOMIA

BIOCHAR DE LODO DE ESGOTO: EFEITOS NO SOLO E NA PLANTA NO CULTIVO DE RABANETE

ALEX ANTÔNIO TORRES CORTÊS DE SOUSA

DISSERTAÇÃO DE MESTRADO EM AGRONOMIA

BRASÍLIA/DF

JANEIRO DE 2015 


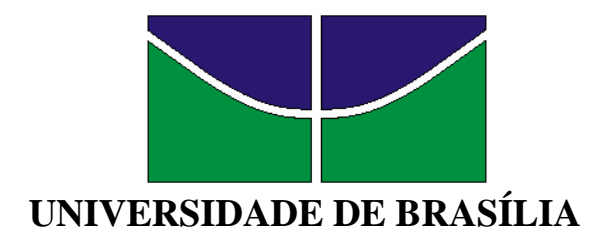

FACULDADE DE AGRONOMIA E MEDICINA VETERINÁRIA PROGRAMA DE PÓS-GRADUAÇÃO EM AGRONOMIA

BIOCHAR DE LODO DE ESGOTO: EFEITOS NO SOLO E NA PLANTA NO CULTIVO DE RABANETE

ALEX ANTÔNIO TORRES CORTÊS DE SOUSA

ORIENTADOR: CÍCERO CÉLIO DE FIGUEIREDO

DISSERTAÇÃO DE MESTRADO EM AGRONOMIA

PUBLICAÇÃO: 80/2015

BRASÍLIA/DF

JANEIRO DE 2015 


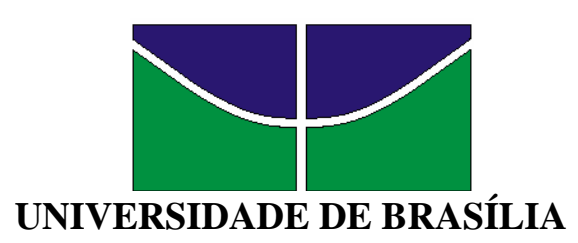

FACULDADE DE AGRONOMIA E MEDICINA VETERINÁRIA

PROGRAMA DE PÓS-GRADUAÇÃO EM AGRONOMIA

\section{BIOCHAR DE LODO DE ESGOTO: EFEITOS NO SOLO E NA PLANTA NO CULTIVO DE RABANETE}

\section{ALEX ANTÔNIO TORRES CORTÊS DE SOUSA}

Dissertação de Mestrado submetido à Faculdade de Agronomia e Medicina Veterinária da Universidade de Brasília - UnB, como parte dos requisitos necessários à obtenção do grau de Mestre em Agronomia.

APROVADO POR:

Cícero Célio de Figueiredo

Professor Doutor, Universidade de Brasília - UnB

Orientador / email: cicerocf@unb.br

Eiyti Kato

Professor Doutor, Universidade de Brasília - UnB

Examinador interno / email: kato@unb.br

Daniel Basílio Zandonadi

Doutor, Embrapa Hortaliças

Examinador externo/ email: daniel.zandonadi@embrapa.br

BRASÍLIA/DF, 30 DE JANEIRO DE 2015 


\section{FICHA CATALOGRÁFICA}

SOUSA, Alex Antônio Torres Cortês de

"BIOCHAR DE LODO DE ESGOTO: EFEITOS NO SOLO E NA PLANTA NO

CULTIVO DE RABANETE”

Orientação: Cícero Célio de Figueiredo, Brasília, 2015. 63 páginas

Dissertação de Mestrado (M) - Universidade de Brasília / Faculdade de Agronomia e Medicina Veterinária, 2015.

1. Biossólido 2.Pirólise 3. Raphanus sativus $\mathrm{L}$

I. Figueiredo, C.C.de. II. Dro ${ }^{\circ}$.

\section{REFERÊNCIA BIBLIOGRÁFICA}

SOUSA, A. A. T. C. Biochar de lodo de esgoto: efeitos no solo e na planta no cultivo de rabanete. Brasília: Faculdade de Agronomia e Medicina Veterinária, Universidade de Brasília, 2015, 63 páginas. Dissertação.

\section{CESSÃO DE DIREITOS}

\section{Nome do Autor: ALEX ANTONIO TORRES CORTES DE SOUSA}

Título da Dissertação de Mestrado: Biochar de lodo de esgoto: efeitos no solo e na planta no cultivo de rabanete.

Grau: Mestre Ano: 2015

É concedida à Universidade de Brasília de Brasília permissão para reproduzir cópias desta dissertação de mestrado para única e exclusivamente propósitos acadêmicos e científicos. O autor reserva para si os outros direitos autorais, de publicação. Nenhuma parte desta dissertação de mestrado pode ser reproduzida sem a autorização por escrito do autor. Citações são estimuladas, desde que citada à fonte.

\section{ALEX ANTONIO TORRES CORTES DE SOUSA}

CPF: 003.098.793-88

QI 06, Conjunto M Casa 21 / CEP: 71.010-134 Guará I, DF. Brasil

(61) 3254-1103/ (61) 8550-5521 / email: acagrocerrado@gmail.com 
Ofereço a todos que participaram dessa fase e que sempre me apoiaram, acreditando, incentivando e dando força.

As pessoas mais importantes na minha vida: Minha família e amigos, em especial a minha filha, Isadora Ferreira Cortês, meu maior amor! 


\section{AGRADECIMENTOS}

A Deus por sempre iluminar minha vida e a das pessoas que amo.

Ao meu professor orientador Dr. Cícero Célio de Figueiredo pelos ensinamentos desde a época da graduação, pela paciência e o voto de confiança, pelo incentivo, pelas cobranças, pela dedicação. Grande Cícero saiba que tens minha admiração, respeito, gratidão e orgulho pelo excelente profissional que és. É um espelho pra mim. Obrigado e Parabéns.

A minha família, minha mãe Rita Célia Torres Cortês de Sousa, meu pai José Edimilson Oliveira de Sousa, meus irmãos Higo Fernando Torres Cortês de Sousa e Iago Torres Cortês de Sousa, minha esposa Lana Mary Gomes Ferreira Cortês, minha filha Isadora Ferreira Cortês e toda família Cortês.

Aos meus supervisores da Embrapa Recursos Genéticos e Biotecnologia Carmen Silva Soares Pires e Edison Ryoitii Sujii pela compreensão, conselhos, ensinamentos e por participarem da minha família embrapiana.

Aos meus amigos embrapianos Márcio Wandré Moraes de Oliveira, Isabella Girotti Grisii, Lucas Machado de Souza, José Gilson de Souza, Helio Moreira dos Santos, Mayra Pimenta, Karoline Torezani, Pedro Togni, Carla Caixeta, Lorena Bravo, Michely Aquino, Samantha, Aline, Dolores, Miniarê, Giselle, Marla.

Aos membros da banca examinadora (Dr. Daniel Zandonadi e Dr. Eiyti Kato) pela disponibilidade e pelas valiosas sugestões.

Ao pessoal do laboratório de matéria orgânica do solo, em especial a Helen, Túlio e Tiago pelo apoio na realização de algumas análises.

Muito Obrigado! 


\section{SUMÁRIO}

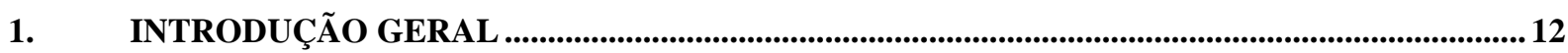

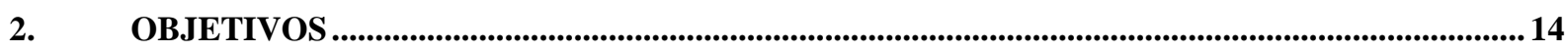

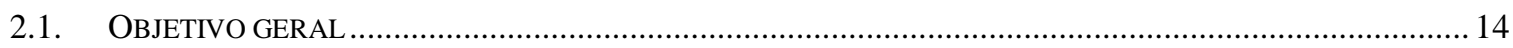

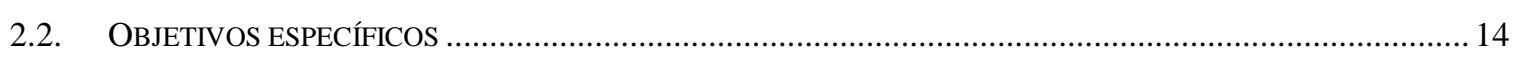

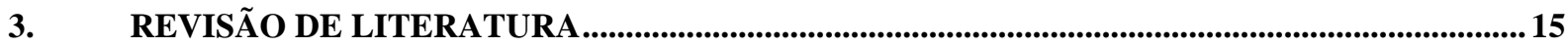

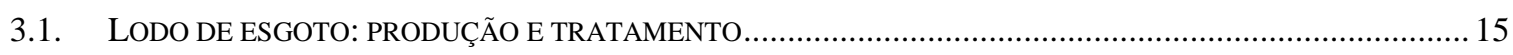

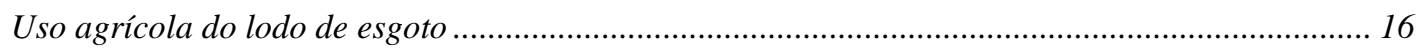

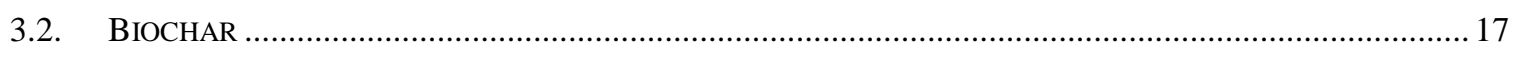

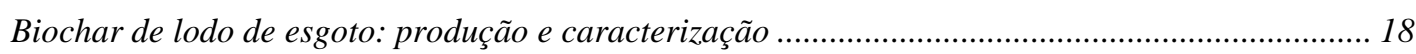

3.3. EFEITOS DO BIOCHAR DO LODO DE ESGOTO NA PRODUÇão AGRÍCOLA ……………………….......... 20

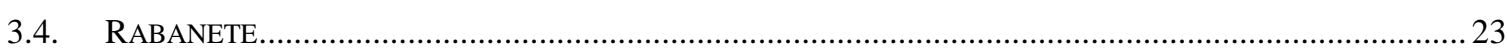

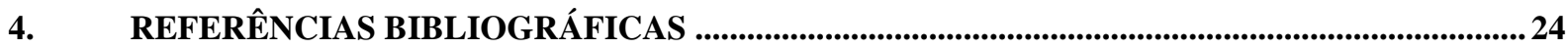

5. BIOCHAR DE LODO DE ESGOTO: EFEITOS NO SOLO E NA PLANTA NO CULTIVO DE

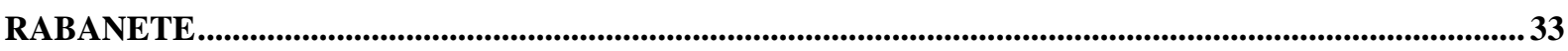

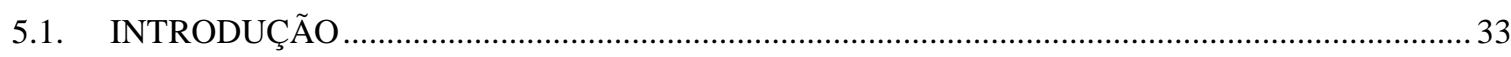

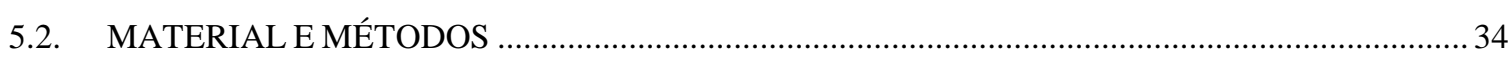

Delineamento experimental .................................................................................................. 35

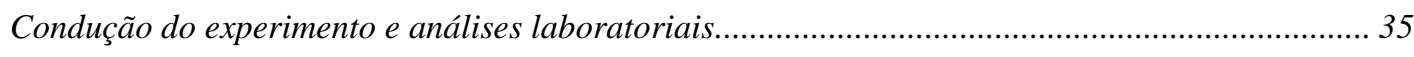

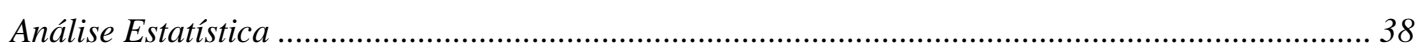

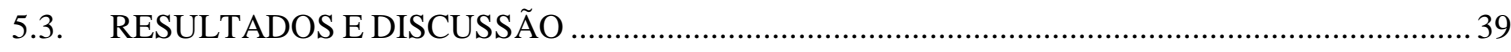

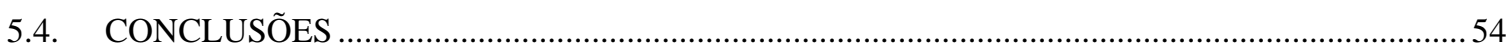

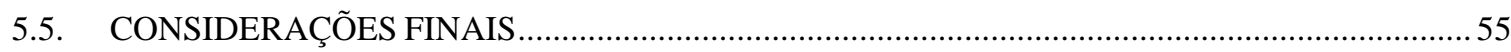

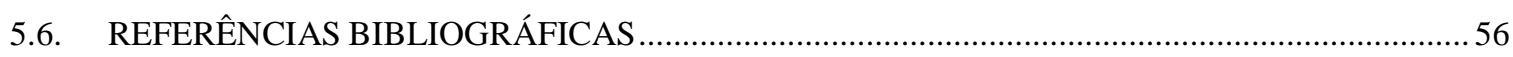




\section{LISTA DE FIGURAS}

Figura 1. Biochar de lodo de esgoto utilizado no experimento. (A): biochar logo após a sua retirada do cadinho, produzido a temperatura de $300^{\circ} \mathrm{C}$ no forno de pirólise (Linn Elektro Therm). (B): biochar sendo preparado para aplicação ao solo, passando-o em peneira de 2 $\mathrm{mm}$.

Figura 2. Desenvolvimento do rabanete em casa de vegetação. (A) plantas de rabanete sendo cultivada em vasos de $2 \mathrm{dm}^{3}$; (B) detalhes do vigor foliar da cultura; (C) aspectos do desenvolvimento da cultura em função da dose crescente de biochar, da esquerda para direita estão as doses 0 a $100 \mathrm{Mg} \mathrm{ha}^{-1}$; (D) detalhes do desenvolvimento do rabanete

Figura 3. Efeito de doses de biochar de LE nos parâmetros biométricos da cultura do rabanete: (A) número de folhas; (B) altura das plantas; (C) comprimento das folhas; (D) massa seca da parte aérea; (E) teor de clorofila medida pelo índice SPAD. Barras verticais indicam o desvio padrão da média. 50

Figura 4. Produtividade estimada do rabanete em resposta à dose de biochar de lodo de esgoto. 


\section{LISTA DE TABELAS}

Tabela 1. Concentração máxima permitida de substâncias inorgânicas em lodo de esgoto ou produtos derivados 16

Tabela 2. Concentração de agentes patogênicos em classes de lodo de esgoto ou produtos

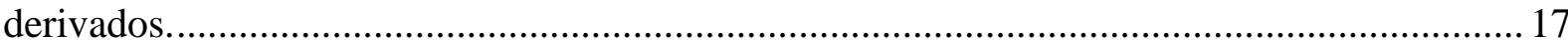

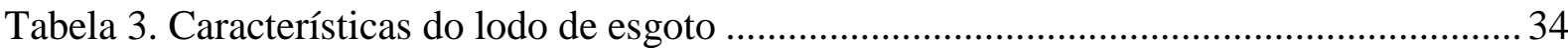

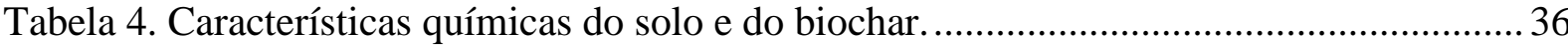

Tabela 5. Propriedades químicas do solo em função da dose de biochar.................................. 40

Tabela 6. Teores de nitrato $\left(\mathrm{NO}_{3}{ }^{-}\right)$e amônio $\left(\mathrm{NH}_{4}{ }^{+}\right)$do solo em resposta à dose de biochar aplicada. 43

Tabela 7. Teores de nutrientes na folha de rabanete em resposta às doses de biochar de lodo de esgoto 


\section{RESUMO}

O biochar tem sido apresentado como uma alternativa viável para o uso agrícola do lodo de esgoto (LE) de forma sustentável. No entanto, ainda há dúvidas sobre os efeitos nutricionais do biochar em culturas de ciclo curto. O objetivo deste estudo foi avaliar o efeito de diferentes doses de biochar de LE nos componentes de fertilidade do solo e no desenvolvimento agronômico do rabanete, Raphanus sativus L. (Brassicae). O biochar de LE foi produzido com temperatura de pirólise de $300^{\circ} \mathrm{C}$, a uma taxa média de aumento de temperatura de $11^{\circ} \mathrm{C}$ $\min ^{-1}$, com um tempo de residência de 30 minutos. Um experimento foi instalado em casa de vegetação, cujo delineamento experimental utilizado foi o inteiramente casualizado com seis tratamentos e quatro repetições. Os tratamentos foram constituídos pelas seguintes doses de biochar, em Mg ha-1 $: 0,0$ (controle); 20; 40; 60; 80; e 100. Foram avaliadas propriedades químicas do solo, antes e após o cultivo do rabanete. O desenvolvimento agronômico da cultura foi avaliado por meio das variáveis: número de folhas, altura da planta, comprimento foliar, massa seca da parte aérea e leitura SPAD. Foram avaliadas, ainda, as concentrações de nutrientes na planta e estimativa da produtividade. As variáveis testadas responderam ao aumento da dose do produto com as melhores respostas obtidas entre as doses de 20 e $60 \mathrm{Mg}$ $\mathrm{ha}^{-1}$, sendo observada uma leve redução a partir da dose $60 \mathrm{Mg} \mathrm{ha}^{-1}$. Quanto às propriedades químicas do solo houve, de maneira geral, um enriquecimento dos nutrientes no solo com a aplicação do biochar. Esse aumento dos teores de nutrientes, principalmente fósforo e nitrogênio, e dos indicadores de fertilidade do solo se refletiram em maior concentração de nutrientes foliares, com respostas no maior desenvolvimento da planta.

Palavras-chave: Biossólido; pirólise; Raphanus sativus L. 


\begin{abstract}
Biochar has been presented as a viable alternative to the agricultural use of sewage sludge in a sustainable way. However, there are still doubts about the nutritional effects of biochar on short cycle crops. The objective of this study was to evaluate the effect of different doses of sewage sludge biochar on soil fertility components and agronomic development of the radish, Raphanus sativus L. (Brassicae). The sewage sludge was produced with biochar $300^{\circ} \mathrm{C}$ pyrolysis temperature at an average rate of temperature rise of $11^{\circ} \mathrm{C} \mathrm{min}^{-1}$ with 30 minutes of residence time. One experiment was conducted in a greenhouse, whose experimental design was completely randomized with six treatments and four replications. The treatments consisted of the following doses of biochar in $\mathrm{Mgha}^{-1}$ : 0.0 (control), 20, 40, 60, 80 and 100 . Soil properties were evaluated before and after cultivation of radishes. The agronomic crop development was evaluated using the variables: number of leaves, plant height, leaf length, dry weight of shoot and index SPAD. Also the concentrations of nutrients in plant was evaluated and yield was estimated. The variables tested responded to the increase in dose of biochar 20 and $60 \mathrm{Mg} \mathrm{ha}^{-1}$, a slight decrease was observed from $60 \mathrm{Mg} \mathrm{ha}^{-1}$. On the chemical properties of the soil was, in general, an enrichment of nutrients in the soil with biochar application. This increase in nutrient levels, particularly phosphorus and nitrogen, and soil fertility indicators were suggested by a greater concentration of foliar nutrients, resulting in the further development of the plant.
\end{abstract}

Key Words: Biosolid; pyrolysis; Raphanus sativus L. 


\section{INTRODUÇÃO GERAL}

No Brasil grande parte da população ainda não é atendida pelos serviços de saneamento básico, o que intensifica a contaminação dos corpos d'água. Do esgoto gerado no Brasil, apenas 37,5 \% recebe algum tipo de tratamento (Trata Brasil, 2013). Por isso, os governos vêm investindo na implantação ou manutenção das estações de tratamento de esgoto (ETE) no país (Junio et al., 2013).

A importância para o Brasil do lodo gerado pelo tratamento de esgoto deve-se às suas possibilidades de uso na agricultura, silvicultura e na recuperação de áreas degradadas, entre outros destinos. Utilizar o LE na agricultura tem sido uma solução viável do ponto de vista agronômico e econômico (Maio et al., 2011; Nascimento et al., 2011). Os benefícios desse resíduo na agricultura têm sido observados em diversas culturas, como fonte nutricional e como melhorador das propriedades do solo (Nascimento et al., 2011).

Embora seja viável a utilização do LE na agricultura, principalmente como fonte de nitrogênio e fósforo, a legislação brasileira através da resolução CONAMA 375 de 2006 limita sua utilização, por possuir componentes tóxicos, como os metais pesados, coliformes fecais, que estão presentes no material em diferentes concentrações (Brasil, 2006). Uma alternativa para atender as exigências da legislação é transformar o LE em um biocarvão identificado internacionalmente por biochar.

O biochar é um material sólido obtido através da conversão termoquímica de diversas biomassas (matérias-primas) em um ambiente sem oxigênio ou com pouco oxigênio e que pode ser utilizado como condicionador do solo e fonte de nutrientes para plantas (International Biochar Initiative, 2012). A idéia de produzir biochar surgiu devido à observação em solos habitados por índios, nos quais eram enterrados restos vegetais e animais e com a ação da natureza esses materiais favoreciam a vida do solo e consequentemente a sua fertilidade. Essa prática de manejo foi melhorando os solos da Amazônia, tornando-os sustentáveis para agricultura de subsistência e foram identificados como Terra Preta de Índio TPI (Cochrane \& Sanchez, 1982).

A possibilidade de se obter um produto com propriedades similares à TPI despertou o interesse de pesquisadores do mundo inteiro, que viram no biochar um material com características adequadas para esta finalidade. Qualquer matéria-prima pode ser utilizada na produção de biochar, principalmente aquela oriunda de plantas lenhosas, desde que não contenha em sua composição mais de $2 \%$ de contaminantes em peso seco (International Biochar Initiative, 2012). Produzir biochar de LE pode viabilizar a utilização desse resíduo na 
agricultura, representando uma excelente alternativa para resolver o problema ambiental gerado pelo acúmulo de lodo nas Estações de Tratamento de Esgoto (ETE). No entanto, estudos com biochar de LE ainda são recentes (Spokas et al., 2012).

O biochar de LE, além de rico em matéria orgânica e nutrientes como nitrogênio e fósforo, aumenta a eficiência dos fertilizantes através das melhorias das propriedades químicas do solo. Com adição de biochar ao solo a capacidade de trocas catiônicas (CTC) aumentou em até $40 \%$ e o potencial hidrogeniônico do solo $(\mathrm{pH})$ em uma unidade (Mikan \& Abrams, 1995). Assim a aplicação de biochar de LE pode diminuir as perdas de nutrientes aplicados ao solo, viabilizar o uso do LE na agricultura e aumentar o seqüestro de carbono no solo (Hossain et al., 2010).

Apesar de seu potencial de uso há ainda carência de estudos no Brasil que relacionam a utilização de biochar de LE com o desempenho agronômico de plantas e sua contribuição na fertilidade do solo. Estudos em outros países vêm mostrando a viabilidade de utilização deste produto na agricultura. Jeffery et al. (2010) verificaram que as culturas com melhores respostas agronômicas após a aplicação de biochar foram soja e rabanete.

O rabanete, Raphanus sativus L., é uma brássica de ciclo curto e apresenta importância econômica e nutricional. É uma cultura exigente quanto à fertilidade do solo. $\mathrm{O}$ seu desenvolvimento é dependente da qualidade da matéria orgânica do solo (Filgueira, 2003). Por possuir ciclo curto essa cultura se torna uma boa opção ao produtor familiar e/ou de pequena escala, que pode ser cultivada entre duas culturas de ciclo mais longo, e possibilitando um retorno financeiro em um tempo mais curto, cerca de 30 dias (Cardoso \& Hiraki, 2001).

Dessa forma, tornam-se importantes estudos que avaliem os efeitos do biochar de LE no desempenho agronômico do rabanete. 


\section{OBJETIVOS}

\subsection{Objetivo geral}

Avaliar o efeito de biochar de LE nas propriedades químicas do solo, na nutrição de plantas e no desenvolvimento agronômico do rabanete.

\subsection{Objetivos específicos}

Verificar os efeitos de doses de biochar de lodo de esgoto:

1. Nas características do rabanete: número de folhas, altura da planta, comprimento da folha, massa seca da parte aérea.

2. No índice SPAD.

3. Nos parâmetros de fertilidade do solo: nitrogênio disponível (nitrato e amônio), fósforo e potássio disponíveis e cátions trocáveis (cálcio e magnésio), componentes da acidez $\left(\mathrm{Al}^{3+}, \mathrm{H}+\mathrm{Al}, \mathrm{pH}\right.$ em $\left.\mathrm{CaCl}_{2}\right)$ e capacidade de troca catiônica no solo.

4. Na concentração de nutrientes nas folhas do rabanete.

5. Na produtividade do rabanete. 


\section{REVISÃO DE LITERATURA}

\subsection{Lodo de esgoto: produção e tratamento}

O lodo de esgoto é resultante do tratamento de águas residuárias, e seu acúmulo em pátios de secagem pode representar um grande problema ambiental. Com a crescente produção de LE e considerando as diversas maneiras de disposição final deste resíduo, sua utilização na agricultura tem se mostrado, mundialmente, como uma solução viável técnica e economicamente, por ser fonte de nutrientes, melhorar as condições físicas do solo e por constituir uma destinação definitiva para esse produto (Andreoli \& Pinto, 2001; Pegorini \& Andreoli, 2006).

O lodo de esgoto é considerado um material rico em matéria orgânica e em nutrientes essenciais para as plantas. No entanto, a sua utilização possui riscos associados à presença de metais tóxicos, microrganismos patogênicos e pela produção ininterrupta em grande escala deste material (Lourênço, 1997).

Atualmente no Brasil 57,1\% da população recebe coleta de esgoto (Trata Brasil, 2013). Isso gera uma grande quantidade de resíduo nas estações de tratamento. Apenas no Distrito Federal a produção atual de LE é de aproximadamente 400 toneladas por dia (Caesb, 2013). O elevado volume de resíduos gerados diariamente e a falta de alternativas viáveis para seu processamento e sua destinação final representam um dos problemas decorrentes de sua produção. Assim, embora indispensáveis para se obter resultados satisfatórios dos serviços de saneamento (Pegorini \& Andreoli, 2006), o tratamento de LE apresenta-se como um processo de grande complexidade e de elevados custos, com dificuldades que muitas vezes ultrapassam os limites das estações de tratamento de água e esgoto, como a falta de infraestrutura que suporte a quantidade gerada.

O tratamento do LE consiste em remover as impurezas e devolvê-lo à natureza sem causar danos ambientais e à saúde humana. De maneira geral a própria natureza consegue decompor a matéria orgânica em rios, lagos e no mar. Entretanto, no caso do LE pela grande quantidade gerada se faz necessário um tratamento mais eficaz e rápido (Caesb, 2013). Esse tratamento é realizado nas Estações de Tratamento de Esgotos (ETEs), que são responsáveis pela remoção das cargas poluentes do esgoto através de processos físicos, químicos ou biológicos, devolvendo à natureza um produto que atenda às exigências legais. Esse 
tratamento consiste em quatro etapas: pré-tratamento, e tratamentos primário, secundário e terciário (Caesb, 2013).

O pré-tratamento consiste em utilizar grades, peneiras ou caixas de areia para reter os resíduos maiores e impedir que haja danos às próximas unidades de tratamento e facilitar o transporte do efluente. Quando começa o tratamento em nível primário os sólidos são sedimentados em suspensão que vão precipitando no fundo do decantador, formando o lodo primário que em seguida é retirado para dar continuidade ao processo.

No tratamento secundário ocorre a ação dos microrganismos, que irão decompor a matéria orgânica, transformando-a em carbono e água. E por último no tratamento terciário há a remoção de poluentes específicos, tais como os nutrientes fósforo e nitrogênio. Esse tratamento que tem a função de estabilizar a matéria orgânica e favorecer a desidratação é realizado por digestores. Após a desidratação, o resíduo é o LE propriamente dito, o qual deve ser encaminhado para destinação final (Caesb, 2013).

\section{Uso agrícola do lodo de esgoto}

No Brasil, a utilização do LE na agricultura é regulamentada pela resolução CONAMA 357 de 2006 e dentro dessa regulamentação há exigências a serem cumpridas quanto ao seu uso (Brasil, 2006). De maneira resumida, essas exigências estabelecem as concentrações máximas de substâncias inorgânicas e a presença de agentes patogênicos, que estão especificadas nas tabelas 1 e 2 , respectivamente.

Tabela 1. Concentração máxima permitida de substâncias inorgânicas em lodo de esgoto ou produtos derivados.

\begin{tabular}{cc}
\hline Substâncias inorgânicas & $\begin{array}{c}\text { Concentração máxima permitida } \\
\left(\mathrm{mg} \mathrm{kg}^{-1}, \text { base seca }\right)\end{array}$ \\
\hline Arsênio & 41 \\
Bário & 1300 \\
Cádmio & 39 \\
Chumbo & 300 \\
Cobre & 1500 \\
Cromo & 1000 \\
Mercúrio & 17 \\
Molibdênio & 50 \\
Níquel & 420 \\
Selênio & 100 \\
Zinco & 2800 \\
\hline
\end{tabular}

Fonte: Resolução CONAMA 375 de 2006. 
Tabela 2. Concentração de agentes patogênicos em classes de lodo de esgoto ou produtos derivados.

\begin{tabular}{cl}
\hline Classe & \multicolumn{1}{c}{ Concentração de patógenos } \\
\hline & Coliformes Termotolerantes $<10^{3} \mathrm{NMP} / \mathrm{g}$ de \\
& ST \\
A & Ovos viáveis de helmintos $<0,25$ ovo / g de \\
& ST \\
& Salmonella: ausência em $10 \mathrm{~g}$ de ST \\
& Vírus $<0,25$ UFP ou UFF $/ \mathrm{g} \mathrm{de} \mathrm{ST}$ \\
\hline & Coliformes Termotolerantes $<10^{6} \mathrm{NMP} / \mathrm{g} \mathrm{de}$ \\
B & ST \\
& Ovos viáveis de helmintos $<10$ ovos / g de \\
& ST
\end{tabular}

Fonte: Resolução CONAMA 375 de 2006.

ST: Sólidos Totais; NMP: Número Mais Provável; UFF: Unidade Formadora de Foco; UFP: Unidade Formadora de Placa

Diante dessas exigências, o reaproveitamento do LE é limitado e, como consequência, grande quantidade desse resíduo se acumula nos pátios de secagem das ETEs, representando um problema ambiental que necessita de solução.

\subsection{Biochar}

Biochar é o produto da pirólise de biomassa (animal ou vegetal), obtido na ausência ou em atmosfera pobre em oxigênio, cuja finalidade é o uso no solo com intuito de aumentar suas reservas de carbono e nutrientes, além de atuar como condicionador/condicionante de solo (International Biochar Initiative, 2012). As características nutricionais variam em função do material utilizado na pirólise, mas normalmente há aumento na capacidade de trocas catiônicas, macronutrientes, micronutrientes e pH (Hossain et al., 2011; Jeffery et al., 2011; Agrafioti et al., 2013; Yuan et al., 2013; Masek et al., 2013).

A pirólise consiste na queima do material sem a presença de oxigênio ou com pouco oxigênio, ou seja, uma decomposição pelo calor ou degradação de um material por energia térmica (Silvério \& Barbosa, 2008). É um processo de oxidação-redução no qual uma parte da biomassa é reduzida a carbono e a outra parte é oxidada e hidrolisada dando origem a fenóis, carboidratos, álcoois, aldeídos, cetonas e ácidos carboxílicos (Rocha et al., 2004).

Existem dois tipos de pirólise: a lenta e a rápida. A lenta consiste em uma sequência de reações com baixas taxas de aquecimento $\left({ }^{\circ} \mathrm{C} / \mathrm{s}\right)$ e longas durações, o que maximiza o rendimento do carvão, diminuindo as quantidades de bio-óleo e gás. A pirólise rápida é 
realizada com elevadas taxas de aquecimento e curtas durações, produzindo principalmente vapores e aerossóis, além de carvão (Lehmann \& Stephen, 2009).

\section{Biochar de lodo de esgoto: produção e caracterização}

Lodo de esgoto, bagaço e palha de cana-de-açúcar e esterco de galinha são alguns resíduos orgânicos que podem ser utilizados para produção de biochar. São gerados em abundância e, normalmente, são aplicados na superfície do solo para atuarem como fertilizantes e/ou condicionadores. A conversão destes resíduos em biochar tem sido usada como alternativa viável para aumentar o seqüestro de carbono em solos (Lehmann et al., 2006).

O biochar de LE pode ser produzido por pirólise em temperaturas que variam de $300^{\circ} \mathrm{C} \mathrm{a}$ $800^{\circ} \mathrm{C}$ (Lehmann \& Stephen, 2009). Estudos com diferentes temperaturas de pirólise com LE mostraram que o maior rendimento foi obtido com a temperatura de $300^{\circ} \mathrm{C}$ por 30 minutos, significando que as reações de pirólise para essa matéria prima são completadas dentro de 30 minutos, sem a necessidade de permanência por longos períodos (Hossain et al., 2011; Agrafioti et al., 2013; Yuan et al., 2013; Masek et al., 2013).

O biochar de LE pode apresentar ampla variação na sua composição e caracterização, conforme a origem e o tipo de tratamento (Hossain et al., 2009). Em recente trabalho realizado por Lopes (2013) comparando a composição química do LE como referência, e o biochar obtido nas temperaturas de $300^{\circ} \mathrm{C}, 400^{\circ} \mathrm{C}$ e $500^{\circ} \mathrm{C}$ foi observado que o obtido a $300^{\circ} \mathrm{C}$, de maneira geral, apresentou os melhores resultados, assemelhando-se ao lodo in natura quanto à composição nutricional. Apresentando também maiores teores de carbono, nitrogênio, hidrogênio, oxigênio, cálcio, enxofre, $\mathrm{pH}$ e massa seca, além de menores valores da relação $\mathrm{C} / \mathrm{N}$, quando comparado aos biochars obtidos em temperaturas mais elevadas (400 e $\left.500{ }^{\circ} \mathrm{C}\right)$.

Outros trabalhos com biochar de LE também mostraram que há um enriquecimento nos teores de carbono, cálcio, cobre, potássio, fósforo, magnésio, ferro, zinco, capacidade de trocas catiônicas e $\mathrm{pH}$, já em relação a condutividade elétrica, nitrogênio e manganês há uma redução nos seus valores conforme aumenta a temperatura de pirólise (Bagreev et al., 2001; Cooger et al., 2006; Chan \& Xu, 2009; Hossain et al., 2010; 2011; Nóbrega, 2011). Quando se analisa o biochar de $\mathrm{LE} \mathrm{a} 300^{\circ} \mathrm{C}$ comparado ao lodo in natura há um aumento nos teores de nitrogênio e carbono e diminuição de hidrogênio (Hossain et al., 2011; Agrafioti et al., 2013; Yuan et al., 2013; Masek et al., 2013). É comum verificar um aumento no pH do solo após a 
transformação do LE em biochar (Gaskin et al., 2008; Singh et al., 2010a; Zhang et al., 2012), demonstrando efeito alcalinizante desse produto, característica importante para aplicação em solos ácidos, como os que predominam no Brasil.

Hossain et al. (2011) também verificaram que o LE pirolisado nas temperaturas de 300, 400 e $500^{\circ} \mathrm{C}$ produziu biochar com enriquecimento relativo (ER), tendo o lodo in natura como referência, maior que 1 para os nutrientes cálcio, magnésio, enxofre, cobre, ferro e zinco. Já para Yuan et al. (2013) o cobre teve seu ER maior na temperatura de $300^{\circ} \mathrm{C}$ e para o zinco o maior ER foi para $500^{\circ} \mathrm{C}$, além do incremento na área superficial e volume de poros do solo.

Quanto aos teores de metais tóxicos contidos no biochar, como cádmio, chumbo, cromo, arsênio, níquel, zinco, diversos autores observaram que após a pirólise a concentração desses metais ficou dentro dos limites aceitáveis para utilização na agricultura, estabelecidos pelas legislações de diversos países, com Austrália, Brasil, China, Portugal, independente da matéria prima pirolisada (Nóbrega, 2011; Hossain et al., 2011; Khan et al., 2013; Yachigo \& Sato, 2013; Milla et al., 2013). No entanto, quando se trata especificamente da matéria prima LE, cuidados devem ser tomados quando esse produto é obtido em centros urbanos industrializados, quando as taxas de metais tóxicos podem ser altas podendo inviabilizar a produção de biochar.

Embora exista uma variação na composição nutricional do biochar, normalmente há um aumento nos teores de matéria orgânica, $\mathrm{CTC}, \mathrm{pH}$, micronutrientes e macronutrientes, com exceção do nitrogênio que apresenta uma leve diminuição. Os maiores teores de carbono são decorrentes do processo de pirólise que preserva a maior parte dos compostos orgânicos. Além disso, o aumento do $\mathrm{pH}$ é resultado da maior concentração de elementos alcalinos, como sódio, cálcio e magnésio, concentração essa favorecida pela crescente volatilização dos elementos hidrogênio, oxigênio e nitrogênio através da pirólise (Hossain et al., 2011; Zhang et al., 2012; Khan et al., 2013). Já os micronutrientes podem ser mais concentrados devido à baixa volatilização, por serem mais recalcitrantes e/ou por estarem em formas inorgânicas (Nóbrega, 2011; Milla et al., 2013; Yachigo \& Sato, 2013). Além disso, alguns elementos só volatilizam em temperaturas de pirólise acima de $700^{\circ} \mathrm{C}$ (Gaskin et al., 2008; Singh et al., 2010a; Agrafioti et al., 2013; Yuan et al., 2013). 


\subsection{Efeitos do biochar do lodo de esgoto na produção agrícola}

Embora sejam conhecidas as qualidades agronômicas do LE, que é rico em matéria orgânica e nutrientes, a sua utilização ainda é limitada pela legislação. A transformação desse produto em biochar pode viabilizar a utilização do LE e contornar as limitações estabelecidas. Avaliando o desempenho agronômico do biochar de LE em plantas de arroz, Khan et al. (2013) observaram aumento na produtividade da cultura, além da diminuição de emissões de gases de efeito estufa com o uso do biochar $550^{\circ} \mathrm{C}$. Já Yachigo \& Sato (2013) não verificaram efeitos conclusivos do biochar 300 e $800^{\circ} \mathrm{C}$ na produção de massa seca em plantas de espinafre e feijão. Entretanto, outros trabalhos realizados com esse produto mostraram viabilidade agronômica da sua utilização (Hossain et al., 2010; 2011; Zhang et al., 2012).

No caso específico do cultivo de rabanete com biochar de LE, Chan et al. (2007) concluíram que houve um efeito positivo na cultura com doses de biochar de LE acima de 50 $\mathrm{Mg} \mathrm{ha}^{-1}$.

O biochar de LE pode ser utilizado como fonte nutricional para plantas. Com a adição desse produto ao solo foi observado aumento no número de frutos, número de grãos, número de espigas, número de perfilhos, peso seco, altura da planta e aumento de rendimento em diferentes cultivos (Hossain et al., 2010; Zhang et al., 2012; Schulz et al., 2013).

Em estudos com biochars obtidos de diversas matérias primas, Lima et al. (2013) observaram que o uso do biochar de esterco bovino no cultivo de berinjela mostrou-se eficiente para os parâmetros número de folhas e altura de mudas beneficiando a produção de mudas. Petter et al. (2012) observaram que o biochar de madeira adicionado ao substrato comercial Germinar $^{\circledR}$ melhorou o desempenho agronômico de mudas de alface com aumento da altura da planta, número de folhas verdadeiras, massa fresca e seca das raízes. Milla et al. (2013) observaram que houve aumento na biomassa, tamanho de raiz, largura das folhas, tamanho das hastes com a aplicação de biochar de casca de arroz à cultura de espinafre.

Em ampla revisão sobre os efeitos do biochar realizada por Jeffery et al. (2011), verificou-se que a adição de biochar ao solo proporciona um ganho na produtividade das culturas, independente do tipo de matéria prima e da taxa de aplicação, com aumento médio de cerca de $10 \%$. Esse ganho se deve a contribuição do biochar no aumento do $\mathrm{pH}$, da capacidade de retenção de água e da disponibilidade de nutrientes. Mesmo que o biochar de diferentes fontes e taxas de aplicação possa contribuir na produtividade de diversas culturas, têm-se observado melhores resultados quando aplicados nas culturas de rabanete e soja, e em doses de $100 \mathrm{Mg} \mathrm{ha}^{-1}$. 
A longevidade do biochar no solo pode chegar a 100 anos, com uma taxa de decomposição baixa, auxiliando assim na mitigação da emissão de $\mathrm{CO}_{2}$ (Jha et al., 2010). Além disso, esses autores observaram a sua viabilidade de utilização na agricultura, com aumento no desenvolvimento das plantas, seja aplicado em conjunto com fertilizantes ou individualmente. Além dos efeitos nas plantas, há benefícios quanto às propriedades do solo como retenção de água, disponibilidade de nutrientes, aumento da porosidade, umidade e atividade microbiana. Outro ponto relevante é que a aplicação do biochar tem efeito redutor das emissões de gases de efeito estufa como $\mathrm{CO}_{2}, \mathrm{~N}_{2} \mathrm{O}$ e $\mathrm{CH}_{4}$.

Considerando o biochar de diferentes matérias primas como fonte nutricional, Biederman \& Harpole (2013) mostraram, por meio de meta-análise, um aumento nos parâmetros altura de planta, número e comprimento de folhas, produtividade, massa seca de raiz e folha quando o biochar foi aplicado junto com fertilizante mineral.

Em um experimento com rabanete e cevada em resposta a aplicação de biochar de pinheiro e salgueiro obtidos em temperaturas de 450 a $650^{\circ} \mathrm{C}$, Nelissen et al. (2014) observaram que não houve diferença entre as doses do produto na resposta das culturas. Biederman \& Harpole (2013) recomendam que o biochar seja aplicado ao solo alguns meses antes do plantio e que a resposta das culturas é maior quando há uma aplicação conjunta do biochar com adubo nitrogenado. Chan et al. (2007) também verificaram incremento de $266 \%$ na biomassa do rabanete com aplicação de $100 \mathrm{Mg} \mathrm{ha}^{-1}$ de biochar associado a $100 \mathrm{~kg}$ de $\mathrm{N}$ $\mathrm{ha}^{-1}$.

Em relação a outros indicadores de qualidade do solo, a utilização do biochar mostrou-se eficaz quanto à preferência das minhocas por solos com biochar e viabilidade na fixação biológica do nitrogênio (Rondon et al., 2007; Van Zwieten et al., 2010).

Em experimento com milho e trigo, com biochar de madeira, Baronti et al. (2010) e Vaccari et al. (2011) sugerem que para ganho de massa seca a dose mais adequada é de $60 \mathrm{Mg}$ $\mathrm{ha}^{-1}$ e também confirmam que o carbono do produto pode ficar no solo por cerca de 100 anos. Entretanto, Jones et al. (2012) testaram o biochar de madeira em experimento de campo com milho e grama e mostraram que não houve o mesmo efeito observado em casa de vegetação, quando o biochar mostrou-se viável agronomicamente.

Quanto aos efeitos ambientais do uso do biochar, Vaccari et al. (2011) observaram maior seqüestro de carbono quando aplicaram o biochar ao solo, mesmo em doses acima de $60 \mathrm{Mg}$ $\mathrm{ha}^{-1}$. De forma semelhante Free et al. (2010) mostraram o efeito mitigador de gases, além da aplicação do produto não afetar a germinação e o crescimento inicial da cultura de milho. 
A hipótese de que o biochar aumenta o seqüestro de carbono no solo foi comprovada por Jeffery et al. (2010) quando aplicaram biochar ao solo e observaram que de 10 a $20 \%$ do componente solúvel do material é mineralizado para $\mathrm{CO}_{2}$ e que os compostos aromáticos e alifáticos podem formar moléculas mais complexas e assim aumentar a resistência a decomposição microbiana.

Em relação a metais tóxicos, diversos trabalhos têm mostrado a eficácia do biochar na imobilização do cádmio, cobre, chumbo, arsênio e zinco, além de redução na biodisponibilidade e fitotoxidade desses metais para as plantas (Park et al., 2011; Beesley \& Marmiroli, 2011). Liu et al. (2014) mostraram que apesar do biochar de LE ter incrementado a concentração de metais tóxicos no solo, como resultado da maior adsorção desses metais, a presença do biochar tornou os metais indisponíveis para as plantas.

Em um estudo sobre o efeito do biochar diretamente nos componentes da matéria orgânica do solo e algumas propriedades químicas do solo Shenbagavalli \& Mahimairaja (2012) concluíram que adição desse produto promoveu aumento dos macronutrientes, ácidos fúlvicos, ácidos húmicos e que houve redução nos teores de amônio e nitrato, além de reduzir também pH após a incubação por 90 dias.

Em um estudo de caso com trigo de inverno Galinatto et al. (2011) avaliaram a economicidade do biochar, desde a produção e utilização como condicionador de solo até as estimativas de seqüestro de carbono. Os autores concluíram que o biochar pode ser rentável, dependendo do preço de mercado do produto e também pode entrar no mercado de compensação de carbono.

Os benefícios da utilização do biochar de citrus para o solo, como na maior retenção de águas, agregação e fertilidade, foram confirmados por Elad et al. (2010) em experimento com tomate e pimenta. Além desses ganhos, os autores observaram que há uma influência positiva no segundo nível trófico, do ponto de vista agronômico, em virtude do aumento da resistência sistêmica na pimenta ao ataque de fungos causadores da podridão cinzenta (Botrytis cinerea) e oídio (Leveillula taurica) e também à praga ácaro branco (Polyphagotarsonemus latus), o que mostra a diversidade na sua utilização na agricultura. Herath et al. (2013) e Elad et al. (2010) obtiveram resultados semelhantes quanto ao aumento de macro e mesoporosidade no solo bem como um potencial em melhorar a drenagem do mesmo após aplicação de biochar.

Efeitos nas propriedades físicas e químicas do solo foram observados por Asai et al. (2009) com a aplicação de biochar melhorando a condutividade hidráulica saturada do solo e do fluxo da seiva na planta. Houve aumento no rendimento de grãos de arroz em solo com 
pouca disponibilidade de fósforo e melhoria na resposta em solo com aplicação de nitrogênio e nitrogênio + fósforo. Quando aplicado isoladamente o biochar mostrou resultados inferiores quanto aos teores de clorofila das folhas, possivelmente devido à redução da disponibilidade de $\mathrm{N}$ no solo. Assim há uma indicação que o biochar sem aplicação conjunta com $\mathrm{N}$ pode reduzir a produtividade em solos pobres nesse nutriente, sugerindo que a melhor maneira de utilizar o biochar é conjugado com adubação química.

\subsection{Rabanete}

O rabanete, Raphanus sativus L., é uma cultura exigente quanto à fertilidade do solo e dependente da qualidade da matéria orgânica do solo (Filgueira, 2003). É uma cultura de ciclo curto, aproximadamente 30 dias e se adapta bem a temperaturas de $8^{\circ} \mathrm{C}$ a $20^{\circ} \mathrm{C}$, mas existe cultivares adaptadas as mais diversas condições climáticas. Torna-se uma boa alternativa para cultivos de pequeno porte, como agricultura familiar e de pequena escala. Pode ser cultivada entre duas culturas de ciclo mais longo, e possibilitando um retorno financeiro em um tempo mais curto, dependendo da cultivar (Cardoso \& Hiraki, 2001).

É uma cultura que se desenvolve bem quando o solo é rico em matéria orgânica e ligeiramente úmido, tendo seu desenvolvimento agronômico dependente da fertilidade do solo, entre outros fatores (Camargo, 1984; Cecílio Filho 1998). Os teores considerados adequados extraídos pelas folhas para uma produção média para macronutrientes $\left(\mathrm{g} \mathrm{kg}^{-1}\right)$ são: $\mathrm{N}$ (30-60), P (3-7); K (40-75), Ca (30-45), Mg (5-12); e micronutrientes ( $\mathrm{mg} \mathrm{kg}^{-1}$ ) são: B (25125), $\mathrm{Cu}$ (5-25), Fe (50-200), Mn (50-250) e Zn (20-250) (Boaretto et al., 2009).

A matéria orgânica do solo como uma ótima opção de incremento na fertilidade do solo vem sendo bastante estudada e utilizada no cultivo de hortaliças, dentre elas o rabanete. Santos et al. (1999) utilizaram doses de composto orgânico de lixo no cultivo de rabanete nas quantidades de 30,60, 90 e $120 \mathrm{Mg} \mathrm{ha}^{-1}$ e os resultados mostraram ganhos da produção de massa seca, tanto da parte aérea quanto das raízes. Costa et al. (2006) produziram rabanete (cultivar Crimson Gigante) com húmus de minhoca e esterco bovino nas doses 15, 30 e 45 $\mathrm{Mg} \mathrm{ha}^{-1}$ e observaram pouca influência desses resíduos na produção da cultura.

A demanda para produção de alimentos mais saudáveis e de maneira sustentável com a utilização de adubação orgânica e compostos orgânicos vem crescendo no Brasil. Uma alternativa de insumo para produção sustentável é a utilização de biochar de LE como fonte nutricional para plantas e também como condicionador e enriquecedor da fertilidade do solo, assim como outros compostos já utilizados tradicionalmente na agricultura. 
Buscando viabilizar a utilização do LE na agricultura a sua transformação em biochar é uma alternativa viável, que além de contribuir com o meio ambiente, pode trazer retorno socioeconômico para agricultura (Hossain et al., 2011; Agrafioti et al., 2013; Yuan et al., 2013; Masek et al., 2013).

\section{REFERÊNCIAS BIBLIOGRÁFICAS}

AGRAFIOTI, E.; BOURAS, G.; KALDERIS, D.; DIAMADOPOULOS, E. Biochar production by sewage sludge pyrolysis. Journal of Analytical and Applied Pyrolysis, 101: 72-78, 2013.

ANDREOLI, C. V.; PINTO, M. A. T. Resíduos Sólidos do Saneamento: Processamento, Reciclagem e Disposição Final. Curitiba-PR: Editora ABES, 2001. 273p.

ASAI, H.; SAMSON, B. K.; STEPHAN, H. M.; SONGYIKHANSUTHOR, K.; HOMMA, K.; KIYONO, Y.; INOUE, Y.; SHIRAIWA, T.; HORIE, T. Biochar amendment techniques for upland rice production in northern Laos: Soil physical properties, leaf SPAD and grain yield. Field Crops Research, 111: 81-84, 2009.

BAGREEV, A.; BANDOZ, T. J.; LOCKE, D. C. Pore structure and surface chemistry of adsorbents obtained by pyrolysis of sewage derived fertilizer. Carbon, 39: 1971-1979, 2001.

BARONTI, S.; ALBERTI, G.; VEDOVE, G. D.; GENNARO, F. D.; FELlET, G.; GENESIO, L.; MIGLIETTA, F.; PERESSOTTI, A.; VACCARI, F. P. The biochar option to improve plant yields: first results from some field and pot experiments in Italy. Italian Journal of Agronomy, 5: 3-11, 2010.

BEESLEY, L.; MARMIROLI, M. The immobilisation and retention of soluble arsenic, cadmium and zinc by biochar. Environmental Pollution, 159: 474-480, 2011.

BIEDERMAN, L. A.; HARPOLE, W. S. Biochar and its effects on plant productivity and nutrient cycling: a meta-analysis. Global Change Biology Bioenergy; 5: 202-214, 2013. 
BOARETTO, A. E.; RAIJ, B. V.; SILVA, F. C.; CHITOLINA, J. C.; TEDESCO, M. J.; CARMO, C. A. F. S. Amostragem, acondicionamento e preparo de amostras de plantas para análise química. In: Manual de análises químicas de solos, plantas e fertilizantes. 2 ed. ver. ampl. Brasília, DF: Embrapa Informação Tecnológica, 2009. 627p.

BRASIL. Ministério do Meio Ambiente. Resolução no 375 de 29 de agosto de 2006. Disponível em: http://www.mma.gov.br/conama/. Acesso em: 11 dezembro de 2013.

CAESB. Companhia de Saneamento Ambiental do Distrito Federal. Disponível em: http://www.caesb.df.gov.br/esgoto/sistemas-de-esgotamento.html. Acesso em: 26 de dezembro de 2013.

CAMARGO, L. S. As hortaliças e seu cultivo. 2a ed. Campinas: Fundação Cargill, 1984. $448 \mathrm{p}$.

CARDOSO, A I. I.; HIRAKI, H. Avaliação de doses e épocas de aplicação de nitrato de cálcio em cobertura na cultura do rabanete. Horticultura Brasileira, Brasília, 19: 328-331, 2001.

CECÍLIO FILHO, A. B. F.; FAQUIN, V.; FURTINI NETO, A. E.; SOUZA, R. J. Deficiência nutricional e seu efeito na produção de rabanete. Científica. Jaboticabal, 26: 231-241, 1998.

CHAN, K. Y.; VAN ZWIETEN, L.; MESZAROS, I.; DOWNIE, A.; JOSEPH, S. Agronomic values of greenwaste biochar as a soil amendment. Australian Journal of Soil Research, 45: 629-634, 2007.

CHAN, K. L.; XU, Z. Biochar: nutrient properties and their enhancement. In: LEHMANN, J.; JOSEPH, S., Biochar for environmental mangement science and technology. Earthscan Publishing, 2009. p. 67-84.

COCHRANE, T. T.; SANCHEZ, P. A. Land resources, soil properties and their management in the Amazon region: a state of knowledge report. Cali; CIAT, 1980. 65 p. 
International Conference on Amazon Land Use and Agricultural Research, Cali, Colombia, 1980.

COOGER, S. G.; FORGE, T. A.; NEILSEN, G. H. Biosolid recycling: nitrogen management and soil ecology. Canadian Journal of Soil Science, 86: 613-620, 2006.

COSTA, C.C.; OLIVEIRA, C. D.; SILVA, C. J.; TIMOSSI, P. C.; LEITE, I. C. Crescimento, produtividade e qualidade de raízes de rabanete cultivadas sob diferentes fontes e doses de adubos orgânicos. Horticultura Brasileira, 24: 118-122, 2006.

ELAD, Y.; DAVID, D. R.; HAREL, Y. M.; BORENSHTEIN, M.; KALIFA, H. B.; SILBER, A.; GRABER, E. R. Induction of systemic resistance in plants by biochar, a soil-applied carbon sequestering agent. Disease Control and Pest Management, 100: 913-921, 2010.

FILGUEIRA, F. A. R. Novo manual de olericultura: agrotecnologia moderna na produção e comercialização de hortaliças. Viçosa-MG: UFV, 2003. 290p.

FREE H. F.; McGILL, C. R.; ROWARTH, J. S.; HEDLEY, M. J. The effect of biochars on maize (Zea mays) germination. New Zealand Journal of Agriculture Research, 53: 1-4, 2010.

GALINATTO, S. P.; YODER, JONATHAN, K. J.; GRANATSTEIN, D. The economic value of biochar in crop production and carbon sequestration. Energy Policy, 39: 6344-6350, 2011.

GASKIN, J. W.; STEINER, C.; HARRIS, K.; DAS, K. C.; BIBENS, B. Effect of lowtemperature pyrolysis conditions on biochar for agricultural use. Transaction of the Asabe, 51: 2061-2069, 2008.

HERATH, H. M. S. K.; CAMPS-ARBESTAIN, M.; HEDLEY, M. Effects of biochar on soil physical properties in two contrasting soils: an alfisol and andisol. Geoderma, 209-210: 188$197,2013$. 
HOSSAIN, M. K.; STREZOV, V.; CHAN, K. Y.; ZIOLKOWSKI, A.; NELSON, P. F. Influence of pyrolysis temperature on production and nutrient properties of wastewater sludge biochar. Journal of Environmental Management, 92: 233-228, 2011.

HOSSAIN, M. K.; STREZOV, V.; CHAN, K. Y.; NELSON, P. F. Agronomic properties of wastewater sludge biochar and bioavailability of metals in production of cherry tomato (Lycopersicon esculentum). Chemosphere, 78: 1167-1171, 2010.

HOSSAIN, M. K.; STREZOV, V.; NELSON, P. F. Thermal characterisation of the products of wastewater sludge pyrolysis. Journal of Analytical and Applied Pyrolysis, 85: 442-446, 2009.

INTERNATIONAL BIOCHAR INITIATIVE. Standardized product definition and product testing guidelines for biochar that is used in soil. 2012. Available at: <http://www.biocharinternational.org/sites/default/files/Guidelines_for_Biochar_That_Is_Used_in_Soil_Final .pdf>. Acesso em: 12 de novembro de 2013.

JHA, P.; BISWAS, A. K.; LAKARIA, B. L.; SUBBA RAO, A. Biochar in agriculture prospects and related implications. Current Science, 99: 1218-1225, 2010.

JEFFERY, L. S.; COLIINS, H. P.; BAILEY, V. L. The effect of young biochar on soil respiration. Soil Biology \& Biochemistry, 42: 2345-2347, 2010.

JEFFERY, L. S.; VERHEIJEN, F. G. A.; VAN DER VELDE, M.; BASTOS, A. C. A quantitative review of the effects of biochar application to soils on crop productivity using meta-analysis. Agriculture, Ecosystems and Environment, 144: 175-187, 2011.

JONES, D. L.; ROUSK, J.; EDWARDS-JONES, G.; DELUCA, T. H.; MURPHY, D. V. Biochar-mediated changes in soil quality and plant growth in a three year field trial. Soil Biology \& Biochemistry, 45: 113-124, 2012.

JUNIO, G. R. Z.; SAMPAIO, A. R.; NASCIMENTO, A. L.; SANTOS, G. B.; SANTOS, L. D. T.; FERNANDES, L. A. Produtividade de milho adubado com composto de lodo de esgoto 
e fosfato natural de Gafsa. Revista Brasileira de Engenharia Agrícola e Ambiental, 17: 706-712, 2013.

KHAN, S.; CHAO, C.; WAQAS, M.; ARP, H. P. H.; ZHU, Y. Sewage sludge biochar influence upon rice (Oryza sativa L) yield, metal bioaccumulation and greenhouse gas emissions from acidic paddy soil. Environmental Science \& Technology, 47: 8624-8632, 2013.

LEHMANN, J.; GAUNT, J.; RONDON, M. Bio-char Sequestration in Terrestrial Ecosystems - A Review. Mitigation and Adaptation Strategies for Global Change, 11: 395-419, 2006.

LEHMANN, J. \& STEPHEN, J. Biochar for environmental management: science and technology. Earthscan, 1: 1-12, 2009.

LIMA, S. L.; OLIVEIRA, S. T.; MARIMON-JUNIOR, B. H.; PETTER, F. A.; TAMIOZZO, S.; BUCK, G. B.; MARIMON, B. S. Biochar as substitute for organic matter in the composition of sustrates for seedlings. Acta Scientiarum, 35: 333-341, 2013.

LIU, T.; LIU, B.; ZHANG, W. Nutrients and heavy metals in biochar produced by sewage sludge pyrolysis: Its application in soil amendment. Polish Journal of Environmental Studies, 23: 271-275, 2014

LOPES, H. M. Caracterização química e física de biocarvão de lodo de esgoto sob diferentes temperaturas de pirólise. Brasília: Faculdade de Agronomia e Medicina Veterinária, Universidade de Brasília, 2013. Monografia. 38p.

LOURÊNÇO, R. S. Utilização de lodo de esgoto aeróbio e calado em florestas. Comunicado técnico número 18. Embrapa Florestas, 1997. 03p.

MAIO, M. M.; SAMPAIO, R. A.; NASCIMENTO, A. L.; PRATES, F. B. S.; RODRIGUES, M. N.; SILVA, H. P. S.; DIAS, A. N.; FREITAS, C. E. S. Atributos físicos do solo, adubado com lodo de esgoto e silicato de cálcio e magnésio. Revista Ceres, 58: 823-830, 2011. 
MASEK, O.; BROWNSORT, P.; CROSS, A.; SOHI, S. Influence of production conditions on the yield and environmental stability of biochar. Fuel, 103: 151-155, 2013.

MILLA, O. V.; RIVERA, E. B.; HUANG, W. J.; CHIEN, C. C.; WANG, Y. M. Agronomic properties and characterization of rice husck and wood biochars and their effect on the growth of water spinach in a field test. Journal of Soil Science and Plant Nutrition, 13: 251-266, 2013.

MIKAN, C. J.; ABRAMS, M. D. Altered forest composition and soil properties of historic charcoal hearths in southeastern Pennsylvania. Canadian Journal of Forest Research, 25: 687-696, 1995.

NASCIMENTO, A. L.; SAMPAIO, R. A.; JÚNIOR, D. S. B.; JUNIO, G. R. Z.; FERNANDES, L. A. Crescimento e produtividade de semente de mamona tratada com lodo de esgoto. Revista Caatinga, 24: 145-151, 2011.

NELISSEN，V.; RUYSSCHAERT, G.; MULLER-STOVER，D.; BODE，S.; COOK, J.; RONSSE, F.; SHACKLEY, S.; BOECKX, P.; HAUGGAARD-NIELSEN, H. Short-term effect of feedstock and pyrolysis temperature on biochar characteristics, soil and crop response in temperate soils. Agronomy, 4: 52-73, 2014.

NÓBREGA, I. P. C. Efeitos do Biochar nas propriedades físicas e químicas do solo: Sequestro de carbono no solo. Lisboa: Instituto Superior de Agronomia, Universidade Técnica de Lisboa, 2011. Dissertação de mestrado. 46p.

PARK, J. H.; CHOPPALA, G. K.; BOLAN, N. S.; CHUNG, J. W.; CHUASAVATHI, T. Biochar reduces the bioavailability and phytotoxicity of heavy metals. Plant and Soil, 348: 439-451, 2011

PEGORINI, E. S.; ANDREOLI, C. V. In: Alternativas de uso de resíduos do saneamento. PROSAB, 1: 1-6, 2006. 
PETTER, F. A.; MARIMON-JUNIOR, B. H.; ANDRADE, F. R.; SCHOSSLER, T. R.; GONÇALVES, L. G.; MARIMON, B. S. Biochar como condicionador de substrato para a produção de mudas de alface. Revista Agrarian, 5: 243-250, 2012.

ROCHA, J. D.; PÉREZ, J. M. M.; CORTEZ, L. A. B. Aspectos teóricos e práticos do processo de pirólise de biomassa, curso internacional "Energia na Indústria de Açúcar e Álcool” UNIFEI, Itajubá, 12-16 de julho de 2004.

RONDON, M. A.; LEHMANN, J.; RAMIREZ, J.; HURTADO, M. Biological nitrogen fixation by common beans (Phaseolus vulgaris L.) increases with bio-char additions. Biology and Fertility of Soils, 43: 699-780, 2007.

SANTOS, C. M. P.R.; FERREIRA, M. C.L.; REIS, P.; BALLESTERO, S. D.; FORTES NETO, P. Efeito de doses crescentes de composto de lixo no desenvolvimento de Raphanus sativus. In: ENCONTRO DE INICIAÇÃO CIENTÍFICA, MOSTRA DE POSGRADUAÇÃO, 4, Taubaté. Anais eletrônicos...Taubaté: UNITAU, 1999.

SCHULZ, H.; DUNST, G.; GLASER, B. Positive effects of composted biochar on plant growth and soil fertility. Agronomy for Sustainable Development, 33: 817-827, 2013.

SHENBAGAVALLI, S.; MAHIMAIRAJA, S. Characterization and effect of biochar on nitrogen and carbon dynamics in soil. International Journal of Advanced Biological Research, 2: 249-255, 2012.

SILVERIO, F. O.; BARBOSA, L. C. A. A pirólise como técnica analítica. Química Nova, 31: 1543-1552, 2008.

SINGH, B.; SINGH, B. P.; COWIE, A. L. Characterisation and evaluation of biochars for their application as a soil amendment. Soil Research, 48: 516-525, 2010.

SPOKAS, K. A.; CANTRELL, K. B.; NOVAK, J. M.; ARCHER, D. W.; I, J. A.; COLLINS, H. P.; BOATENG, A. A.; LIMA, I. M.; LAMB, M. C.; MCALOON, A. J.; LENTZ, R. D.; 
NICHOLS, K. A. Biochar: A synthesis of its agronomic impact beyond carbon sequestration. Journal of Environmental Quality, special section: 973-989, 2012.

TRATA BRASIL. Saneamento é Vida. Disponível em: http://www.tratabrasil.org.br/situacao-do-saneamento-no-brasil. Acesso em: $20 \mathrm{de}$ dezembro de 2013.

VACCARI, F. P.; BARONTI, E. L.; GENESIO, L.; CASTALDI, S.; FORNASIER, F. MIGLIETTA, F. Biochar as a strategy to sequester carbon and increase yield in durum wheat. European Journal of Agronomy, 34: 231-238, 2011.

Van ZWIETEN, L.; KIMBER, S.; MORRIS, S.; CHAN, K. Y.; DOWNIE, A. RUST, J.; JOSEPH, S.; COWIE, A. Effects of biochar from slow pyrolysis of papermill waste on agronomic performance and soil fertility. Plant and Soil, 327: 235-246, 2010.

YACHIGO, M.; SATO, S. Leachability and Vegetable Absortion of Heavy Metal from Sewage Sludge Biochar. In: SORIANO, M. C. H. Soil Processes and Current Trends in Quality Assessment. Environmental Sciences, 1: 399-416, 2013.

YUAN, H.; LU, T.; ZHAO, D.; HUANG, H.; NORIYUKI, K.; CHEN, Y. Influence of temperature on product distribution and biochar properties by municipal sludge pyrolysis. Journal Material Cycles Waste Management, 15: 375-361, 2013.

ZHANG, A.; BIAN, R.; PAN, G.; CUI, L.; HUSSAIN, Q.; LI, L.; ZHENG, J.; ZHANG, X.; HAN. X.; YU, X. Effects of biochar amendment on soil quality, crop yield and greenhouse gas emission in a Chinese rice paddy: A field study of 2 consecutive rice growing cycles. Field Crops Research, 127: 153-160, 2012. 


\section{CAPÍTULO ÚNICO}

Biochar de lodo de esgoto: efeitos no solo e na planta no cultivo de rabanete. 


\section{BIOCHAR DE LODO DE ESGOTO: EFEITOS NO SOLO E NA PLANTA NO CULTIVO DE RABANETE}

\subsection{INTRODUÇÃO}

O lodo produzido nas estações de tratamento de esgoto é um dos resíduos mais difíceis para se manejar devido à grande quantidade gerada e à presença de organismos patogênicos (Hossain et al., 2010). Só no Distrito Federal são geradas, aproximadamente, 146.000 toneladas por ano (CAESB, 2014). Um destino adequado para esse resíduo representa interesse de toda a sociedade e, por isso, diversas alternativas de uso têm sido propostas e estudadas.

O biochar é o produto da pirólise de diversas matérias primas, seja animal ou vegetal. Seu uso tem sido indicado, entre muitas finalidades, como condicionador do solo e fonte nutricional para plantas, além de reduzir a emissão de gases de efeito estufa (International Biochar Initiative, 2012; Shenbagavalli \& Mahimairaja, 2012). Entre as diversas matérias primas utilizadas para a produção de biochar, o LE apresenta grande potencial, cujo biochar possui características físicas, químicas e biológicas desejáveis para aumentar a produtividade de culturas agrícolas de forma sustentável, com ganhos ambientais e sociais (Spokas et al., 2012; Shenbagavalli \& Mahimairaja, 2012).

Entre os benefícios apresentados pelo biochar para a melhoria do solo e aspectos ambientais, destacam-se o aumento dos teores de nutrientes de maneira geral, elevação do $\mathrm{pH}$, melhoria na retenção de água e da porosidade (Shenbagavalli \& Mahimairaja, 2012; Biederman \& Harpole, 2013; Herath et al., 2013), diminuição das emissões de gases de efeitos estufa (Free et al., 2010; Vaccari et al., 2011), assim como a redução e imobilização de metais tóxicos como arsênio, cádmio e zinco (Beesley \& Marmiroli, 2011; Park et al., 2011).

A aplicação de biochar como fertilizante pode elevar a produtividade de diversas culturas, com aumento médio de 10\%, como apresentado na ampla revisão realizada por Jeffery et al. (2011). Esse ganho médio de 10\% pode ser considerado pequeno, como apontado por Schulz et al. (2013), devido a grande variedade de culturas, matérias primas e processos de obtenção do biochar.

No caso específico do biochar de LE, ainda são poucos os trabalhos que avaliam os seus benefícios para a fertilidade do solo em culturas de ciclo curto. Entretanto, as elevadas concentrações de nutrientes como nitrogênio e fósforo no LE indicam o potencial do biochar 
para aumentar a disponibilidade de nutrientes do solo em curto prazo. Além disso, aplicação de biochar de LE pode reduzir as perdas de nutrientes aplicados por meio de adubos minerais, além de aumentar o sequestro de carbono no solo e possibilitar a sua utilização na agricultura (Hossain et al., 2010).

Dessa forma, espera-se que o biochar possa viabilizar o uso do LE de forma sustentável como um melhorador da fertilidade do solo com disponibilidade de nutrientes para culturas de ciclo curto e exigentes em nutrientes como o rabanete. Por possuir ciclo curto essa cultura se torna uma boa opção ao produtor familiar e/ou de pequena escala, que pode ser cultivada entre duas culturas de ciclo mais longo, possibilitando um retorno financeiro em um tempo mais curto, em cerca de 30 dias (Cardoso \& Hiraki, 2001).

O objetivo deste trabalho foi avaliar o efeito de doses crescentes de biochar de LE nos atributos de fertilidade do solo e no desenvolvimento da planta de rabanete.

\subsection{MATERIAL E MÉTODOS}

O experimento foi realizado em casa de vegetação com controle de temperatura (média de $25^{\circ} \mathrm{C}$ ) e umidade (média de $60 \%$ ) localizada na Embrapa Recursos Genéticos e Biotecnologia, Brasília, DF, cujas coordenadas são: S $15.73058^{\circ}$ O $047.90047^{\circ}$ e altitude de $960 \mathrm{~m}$.

Foi utilizado biochar produzido a partir de amostras de LE coletadas na Estação de Tratamento de Esgoto (ETE) do Gama, pertencente à Companhia de Saneamento Ambiental do Distrito Federal (CAESB), localizada a $34 \mathrm{~km}$ do centro de Brasília, DF. Esta ETE utiliza o sistema de tratamento em nível secundário, no qual o lodo é tratado em digestores que têm a função de estabilizar a matéria orgânica. O lodo utilizado encontrava-se armazenado em pátio de secagem e algumas propriedades são apresentadas na Tabela 3.

Tabela 3. Características do lodo de esgoto

\begin{tabular}{lcc}
\hline Parâmetro & Unidade & Valor \\
\hline Umidade $\left(65^{\circ} \mathrm{C}\right)$ & $\mathrm{g} \mathrm{g}^{-1}$ & 0,17 \\
Sólidos voláteis & $\mathrm{g} \mathrm{g}^{-1}$ & 0,45 \\
Cinzas & $\mathrm{g} \mathrm{g}^{-1}$ & 0,54 \\
\hline
\end{tabular}

Foi utilizado aproximadamente $1,5 \mathrm{~kg}$ de biomassa de LE, passada por peneira com malha de $8 \mathrm{~mm}$, submetido à temperatura de $300^{\circ} \mathrm{C}$, em forno de pirólise (Linn Elektro Therm), localizado no Laboratório de Preservação e Qualidade da Madeira, pertencente à Universidade de Brasília. A pirólise foi realizada a uma taxa média de aumento de 
temperatura de $11^{\circ} \mathrm{C} \min ^{-1}$, com um tempo de residência de 30 minutos. As amostras foram colocadas em um recipiente de metal adaptado ao espaço interno do forno que contém um sistema de saída de gases e bio-óleo, com mecanismo para evitar o fluxo de oxigênio. $\mathrm{O}$ controle de temperatura durante a pirólise foi realizado com o uso de um termopar tipo K de penetração (modelo MTK-15) acoplado a um termômetro digital KT-160A. Após a pirólise, o biochar foi pesado, acondicionado e peneirado em peneira com malha de $2 \mathrm{~mm}$ (figura 1). As características químicas do biochar são apresentadas na tabela 4.
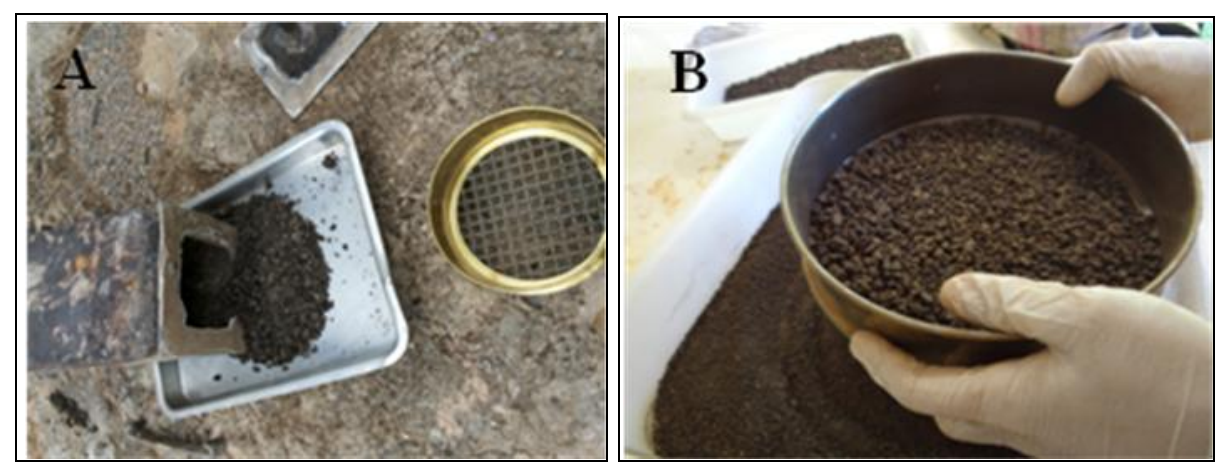

Figura 1. Biochar de lodo de esgoto utilizado no experimento. (A): biochar logo após a sua retirada do cadinho, produzido a temperatura de $300^{\circ} \mathrm{C}$ no forno de pirólise (Linn Elektro Therm). (B): biochar sendo preparado para aplicação ao solo, passando-o em peneira de 2 $\mathrm{mm}$.

\section{Delineamento experimental}

Foi utilizado o delineamento inteiramente casualizado com seis tratamentos e quatro repetições. Os tratamentos foram constituídos pelas seguintes doses de biochar: 0, 20, 40, 60, 80 e $100 \mathrm{Mg} \mathrm{ha}^{-1}$, correspondendo às seguintes porcentagens de biochar em relação à massa de solo (m/m): $0 \%, 1 \%, 2 \%, 3 \%, 4 \%$ e $5 \%$. Estas doses de biochar foram misturadas a $2 \mathrm{~kg}$ de solo em vasos com volume de $2 \mathrm{dm}^{3}$.

\section{Condução do experimento e análises laboratoriais}

Foi utilizada terra obtida de Latossolo Vermelho, textura muito argilosa, cujas características químicas são apresentadas na tabela 4. O solo utilizado no experimento foi analisado antes e ao final do experimento, após a colheita do rabanete. Para isso, as amostras de solo foram secas ao ar e os restos culturais separados. Sub-amostras do solo seco foram passadas em peneira de malha $2 \mathrm{~mm}$ e determinados os teores de nitrogênio disponível 
(nitrato e amônio), fósforo e potássio disponíveis, cátions trocáveis (cálcio e magnésio), componentes da acidez $\left(\mathrm{Al}^{3+}, \mathrm{H}+\mathrm{Al}^{3+}, \mathrm{pH}\right.$ em $\left.\mathrm{CaCl}_{2}\right)$ e capacidade de troca catiônica. As propriedades relacionadas à fertilidade do solo foram determinadas conforme metodologia da Embrapa (1997). Nitrato e amônio foram determinados de acordo com Chitolina et al. (2009).

Tabela 4. Características químicas do solo e do biochar.

\begin{tabular}{|c|c|c|}
\hline Propriedade Química & Solo & BC 300 \\
\hline CT (\%) & - & 23,4 \\
\hline NT (\%) & - & 3,3 \\
\hline $\mathrm{NO}_{3}^{-}\left(\mathrm{mg} \mathrm{kg}^{-1}\right)$ & - & 17,5 \\
\hline $\mathrm{NH}_{4}^{+}\left(\mathrm{mg} \mathrm{kg}^{-1}\right)$ & - & 431,9 \\
\hline Ácido Fulvico $\left(\mathrm{g} \mathrm{kg}^{-1}\right)$ & - & 24,2 \\
\hline Ácido Húmico $\left(\mathrm{g} \mathrm{kg}^{-1}\right)$ & - & 19,4 \\
\hline Humina $\left(\mathrm{g} \mathrm{kg}^{-1}\right)$ & - & 74,8 \\
\hline$P\left(\mathrm{~g} \mathrm{~kg}^{-1}\right)$ & 0,00318 & 41,1 \\
\hline $\mathrm{K}^{+}\left(\mathrm{g} \mathrm{kg}^{-1}\right)$ & 0,029 & 0,16 \\
\hline $\mathrm{Ca}^{+2}$ & $1,24^{\mathrm{a}}$ & $9,7^{\mathrm{b}}$ \\
\hline $\mathrm{Mg}^{+2}$ & $0,30^{\mathrm{a}}$ & $1,8^{\mathrm{b}}$ \\
\hline $\mathrm{S}\left(\mathrm{g} \mathrm{kg}^{-1}\right)$ & - & 15,1 \\
\hline $\mathrm{Al}^{+3}\left(\mathrm{cmol}_{\mathrm{c}} \mathrm{kg}^{-1}\right)$ & 0,02 & - \\
\hline $\mathrm{H}+\mathrm{Al}^{3+}\left(\mathrm{cmol}_{\mathrm{c}} \mathrm{kg}^{-1}\right)$ & 2,30 & - \\
\hline $\mathrm{SB}\left(\mathrm{cmol}_{\mathrm{c}} \mathrm{kg}^{-1}\right)$ & 1,61 & - \\
\hline $\mathrm{t}\left(\mathrm{cmol}_{\mathrm{c}} \mathrm{kg}^{-1}\right)$ & 1,63 & - \\
\hline $\mathrm{T}\left(\mathrm{cmol}_{\mathrm{c}} \mathrm{kg}^{-1}\right)$ & 3,9 & - \\
\hline $\mathrm{V}(\%)$ & 41,3 & - \\
\hline $\mathrm{B}\left(\mathrm{mg} \mathrm{kg}^{-1}\right)$ & - & 9,1 \\
\hline $\mathrm{Cu}\left(\mathrm{mg} \mathrm{kg}^{-1}\right)$ & - & 1,4 \\
\hline $\mathrm{Fe}\left(\mathrm{mg} \mathrm{kg}^{-1}\right)$ & - & 450 \\
\hline $\operatorname{Mn}\left(\mathrm{mg} \mathrm{kg}^{-1}\right)$ & - & 1,0 \\
\hline $\mathrm{Zn}\left(\mathrm{mg} \mathrm{kg}^{-1}\right)$ & - & 5,3 \\
\hline $\mathrm{pH}\left(\mathrm{CaCl}_{2}\right)$ & 6,5 & 6,0 \\
\hline
\end{tabular}

CT: Carbono total; NT: Nitrogênio total; LE: Lodo de Esgoto; BC: Biochar $300^{\circ} \mathrm{C}^{\text {a }} \mathrm{cmol}_{\mathrm{c}} \mathrm{kg}^{-1} ;{ }^{\mathrm{b}} \mathrm{g} \mathrm{kg}^{-1}$.

O rabanete, $R$. sativus L. (cultivar Crimson Gigante), foi semeado diretamente no vaso em 10 de março de 2014 e cultivado em casa de vegetação. Foram semeadas três sementes por 
vaso e, após sete dias da semeadura, realizadas o desbaste, deixando apenas uma planta por vaso. Durante o ciclo da cultura foram realizadas irrigações diárias de $100 \mathrm{ml}$ de água por planta e monitoramento quanto ao ataque de pragas e doenças, mantendo todas as plantas sadias até o final do ciclo. Aos 35 dias após a germinação foram avaliadas as seguintes características: número de folhas, altura da planta, comprimento da folha e massa seca da parte aérea. As características (altura de planta e comprimento de folha) foram medidas com auxílio de um paquímetro, para número de folhas foi realizada contagem direta e a massa seca da parte aérea foi realizada de acordo com Boaretto et al. (2009), colocando a massa fresca da parte aérea em sacos de papel e deixando-a em estufa por 72 horas a $60^{\circ} \mathrm{C}$ e posteriormente pesando com auxílio de balança de precisão Bioprecisa. A produtividade foi determinada através do peso fresco da parte comercializável (tubérculo) por planta, utilizando a mesma balança de precisão, considerando um espaçamento de $15 \mathrm{~cm}$ entre linhas e $5 \mathrm{~cm}$ entre plantas e um total de 1.320 .000 plantas por hectare.

Aos 25 dias após a germinação, como parâmetro fisiológico, foi avaliada a leitura SPAD na folha totalmente sadia e completamente expandida, utilizando um sistema portátil SPAD. Antes de cada leitura o equipamento foi calibrado conforme manual.

Para análise foliar foram determinados os teores de macro e micronutrientes, conforme metodologia desenvolvida por Malavolta et al. (1989). Sendo que o nitrogênio foi determinado por análise semi-micro-Kjeldahl, com transformação do nitrogênio amoniacal $\left(\mathrm{NH}_{4}\right)_{2} \mathrm{SO}_{4}$ em amônia $\left(\mathrm{NH}_{3}\right)$, a qual é fixada pelo ácido bórico e posteriormente titulada com $\mathrm{H}_{2} \mathrm{SO}_{4}$ até nova formação de $\left(\mathrm{NH}_{4}\right)_{2} \mathrm{SO}$ na presença de indicador de ácido/base; fósforo por colorimetria do metavanadato, com formação de um composto amarelo do sistema vanadomolibdofosfórico em acidez 0,2 a $1,6 \mathrm{~N}$; potássio por espectrometria de absorção atômica, com lâmpada de cátodo oco de $\mathrm{K}(\mathrm{Lc})$; enxofre por turbimetria do sulfato de bário, baseado na turbidez formada pela precipitação do enxofre pelo cloreto de bário, na forma de bário, medida por transmitância ou absorbância; cálcio, magnésio, por espectrofotometria de absorção atômica, com o mesmo princípio utilizado para potássio, utilizando-se, porém, lâmpada de arco de descarga de cálcio-magnésio; manganês, cobre e zinco por espectrofotometria de absorção atômica, com determinação direta no extrato nítricoperclórico de vegetais, usando a lâmpada de cátodo oco ou correspondente. 


\section{Análise Estatística}

Os dados foram submetidos à análise de regressão e as significâncias dos modelos foram avaliadas pelo teste F, utilizando-se o software XLSTAT 2013 (Addinsoft, 2013). Também foi realizada análise de variância e teste de comparação de médias (Tukey, p<0,05). 


\subsection{RESULTADOS E DISCUSSÃO}

\section{Efeitos do biochar de lodo de esgoto nas propriedades químicas do solo}

A aplicação de biochar de LE aumentou os teores de nutrientes do solo, com exceção de potássio, e elevou os valores dos indicadores de fertilidade do solo representados pela saturação por bases, CTC e a soma de bases (Tabela 5). De maneira geral, a melhoria da fertilidade do solo foi proporcional à dose de biochar aplicada. Entretanto, o pH do solo que já se encontrava corrigido não sofreu alteração com o aumento da dose de biochar aplicada.

A maior diferença entre doses foi verificada para o fósforo cujos teores se elevaram de 0,39 (dose 0) para 100,31 $\mathrm{mg} \mathrm{dm}^{-3}$ (dose $100 \mathrm{Mg} \mathrm{ha}^{-1}$ ), com incremento de 257 vezes. Esse aumento nos teores de $\mathrm{P}$ disponível no solo é decorrente da elevada concentração desse nutriente no biochar $\left(41,1 \mathrm{~g} \mathrm{~kg}^{-1}\right)$. Com o processo de pirólise há perdas de $\mathrm{C}, \mathrm{H}, \mathrm{O}$ e $\mathrm{N}$ por volatilização e com isso a concentração de $\mathrm{P}$ é favorecida no biochar. O P existente no LE está predominantemente na fração inorgânica, que é mais estável a perdas por volatilização; estas perdas só ocorrem com temperaturas de pirólise acima de $700^{\circ} \mathrm{C}$ (Gaskin et al., 2008; Hossain et al., 2011, Yuan et al., 2013). O pH também influencia a disponibilidade de fósforo, pois em solos ácidos ou alcalinos há precipitação do $\mathrm{P}$ com óxidos de ferro e alumínio (ácidos) e com cálcio (alcalinos), formando minerais como estrengita, variscita e monetita, respectivamente. $\mathrm{O} \mathrm{pH}$ do solo estava corrigido ( $\mathrm{pH}$ em $\mathrm{CaCl}_{2}$ entre 6,20 e 6,35), fator que pode justificar a grande concentração de $\mathrm{P}$ no solo com aplicação do biochar, por ser rico em $\mathrm{P}$ e estar com $\mathrm{pH}$ considerado adequado, favorecendo a disponibilidade desse nutriente no solo (Faquin, 2005; Atkinson et al., 2010; Uzoma et al., 2011). Outro benefício que o biochar promove na disponibilidade de $\mathrm{P}$ no solo é decorrente da sua elevada quantidade de microporos que funcionam como habitat e favorecem o desenvolvimento de microrganismos, que aumentam a disponibilidade desse nutriente (Fischer \& Glaser, 2012). Além disso, Prakongkep et al. (2014) demonstraram que o biochar é rico em fosfato monopotássico $\left(\mathrm{KH}_{2} \mathrm{PO}_{4}\right)$, forma de $\mathrm{P}$ bastante solúvel em água, e de elevada disponibilidade. Esse fornecimento de $\mathrm{P}$ pelo biochar de LE reforça a função nutricional desse produto, fundamental para solos tropicais como os latossolos que predominam no Cerrado, que naturalmente apresentam baixíssimos teores de $\mathrm{P}$ disponível. 
Tabela 5. Propriedades químicas do solo em função da dose de biochar.

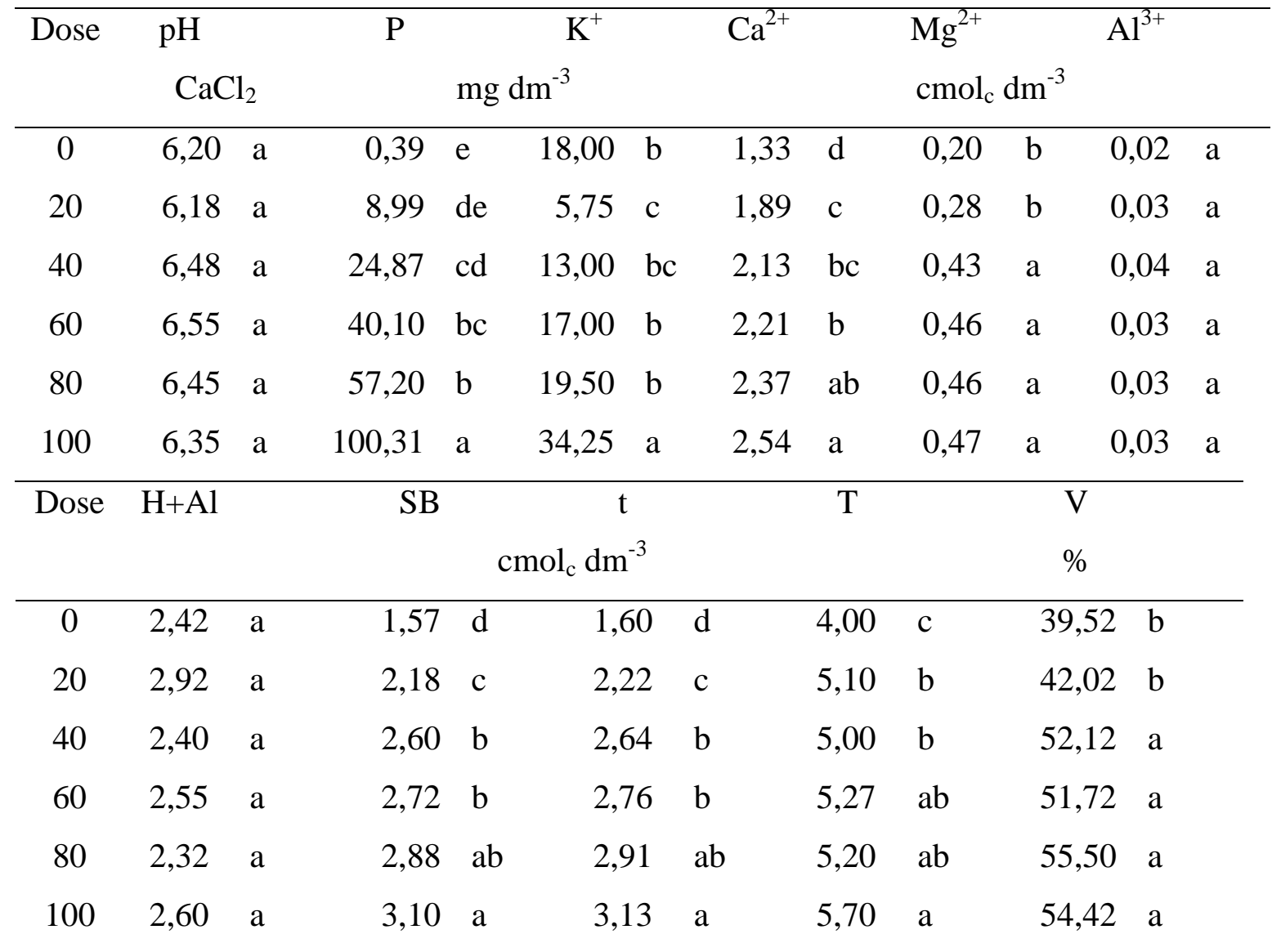

Médias seguidas pelas mesmas letras na coluna não diferem entre si pelo teste de Tukey a 5\%.

Diferentemente do fósforo, a concentração de potássio teve pouca variação com a adição do biochar. Apenas a aplicação de $100 \mathrm{Mg} \mathrm{ha}^{-1}$ de biochar foi suficiente para suprir a planta e aumentar o teor de $\mathrm{K}$ no solo. Com o fornecimento de $20 \mathrm{Mg} \mathrm{ha}^{-1}$, após o cultivo do rabanete, houve redução dos teores iniciais de $\mathrm{K}$ do solo, com balanço negativo desse nutriente no solo. Com exceção da dose de $100 \mathrm{Mg} \mathrm{ha}^{-1}$, os teores de $\mathrm{K}$ nos demais tratamentos foram considerados baixos (Sousa \& Lobato, 2004), indicando que o fornecimento de potássio pela aplicação de biochar de LE só é suficiente em doses iguais ou superiores a $100 \mathrm{Mg} \mathrm{ha}^{-1}$. Embora o teor de $\mathrm{K}$ no biochar $\left(0,16 \mathrm{~g} \mathrm{dm}^{-3}\right)$ seja considerado alto, a sua concentração no solo após o cultivo de rabanete foi considerada baixa (Sousa \& Lobato, 2004), essa diminuição pode ser decorrente do processo de lixiviação, pois durante o ciclo da cultura foram realizadas irrigações diárias com $100 \mathrm{ml}$ de água por planta. Outro fator que pode ter contribuído para lixiviação do $\mathrm{K}$ foi a baixa CTC do solo. O K em solos com baixa CTC tende a permanecer na solução do solo e assim aumentam as condições para a lixiviação (Ernani et al., 2007). Isso também pode ser decorrente dos teores de $\mathrm{Ca}$ no solo, considerados adequados, que podem 
deslocar o K e facilitar a lixiviação desse nutriente (Tammeorg et al., 2014). Embora os teores de K estivessem baixos no solo, houve incremento desse nutriente com a dose de $100 \mathrm{Mg} \mathrm{ha}^{-1}$. Oram et al. (2014) e Tammeorg et al. (2014) constataram acréscimos nos teores de K com adição de $10 \mathrm{Mg} \mathrm{ha}^{-1}$ de biochar de madeira ao solo. Contudo, alguns autores ressaltam que o LE é uma matéria prima que apresenta baixa concentração de K, exigindo elevadas doses de LE quando se busca o fornecimento desse nutriente às plantas (Nascimento et al., 2004; Junio et al., 2013). Alternativas como co-produção do biochar com matéria-prima rica em potássio devem ser buscadas para tornar o biochar de LE uma fonte mais completa de nutrientes para as plantas.

O cálcio apresentou o mesmo comportamento do fósforo quando do fornecimento de biochar ao solo. Os teores desse nutriente aumentaram gradativamente com o aumento da dose de biochar aplicada. Todas as doses de biochar proporcionaram níveis de cálcio adequados para os solos do Cerrado (Sousa \& Lobato, 2004). Em solos ácidos, o suprimento de cálcio ao solo está normalmente ligado à prática de calagem (Neto et al., 2001). Com a adição de biochar pode-se aumentar a disponibilidade desse nutriente, com efeito adicional ao da calagem. Os altos teores de $\mathrm{Ca}$ em biochars são atribuídos à presença de minerais como calcita, anortita, augita e hornblenda (Yuan et al. 2011; Chintala et al., 2014; Smider \& Singh, 2014). Gaskin et al. (2008) e Singh et al. (2010a) citam que os biochars de maneira geral são ricos em Ca e com o processo de pirólise a concentração desse nutriente no biochar é favorecido pela crescente volatilização de C, H, O e N.

O biochar também incrementou os teores de $\mathrm{Mg}^{2+}$ no solo com dose a partir de $40 \mathrm{Mg} \mathrm{ha}^{-}$ 1, sem diferenciação, entretanto, entre as doses superiores a essa. Embora haja um aumento no teor desse nutriente no solo em função da dose de biochar, todos os teores apresentados foram considerados baixos no solo (Sousa \& Lobato, 2004). Assim como o cálcio, em solos ácidos, o suprimento de magnésio ao solo está relacionado à prática de calagem, sendo importante prática quando o teor do elemento no solo é menor que $0,5 \mathrm{cmol}_{\mathrm{c}} \mathrm{dm}^{-3}$ (Sousa \& Lobato, 2004). Da mesma forma que acontece com $\mathrm{P}, \mathrm{K}$ e Ca a concentração de $\mathrm{Mg}^{2+}$ aumenta com o processo de pirólise (Gaskin et al., 2008). Portanto, no presente estudo, a baixa temperatura de pirólise pode ter limitado a contribuição do biochar de LE no fornecimento de $\mathrm{Mg}^{2+}$ em níveis adequados no solo. Além disso, a elevada absorção pelo rabanete e a lixiviação podem ter diminuído a disponibilidade desse nutriente no solo após o cultivo.

Visto que o solo estava com $\mathrm{pH}$ adequado, não houve efeito do biochar sobre os componentes da acidez do solo $\left(\mathrm{pH}, \mathrm{Al}^{3+}\right.$ e $\left.\mathrm{H}+\mathrm{Al}\right)$. Normalmente, são verificados efeitos 
alcalinizantes do biochar, pelo fornecimento de cátions de caráter básicos para solução do solo (Gaskin et al., 2008; Singh et al., 2010a; Zhang et al., 2012; Smider \& Singh, 2014).

A aplicação de biochar aumentou os valores dos indicadores de fertilidade do solo (SB, CTC efetiva e saturação por bases), como resultado do aumento da disponibilidade de cátions trocáveis de caráter básico como $\mathrm{Ca}^{2+}$ e $\mathrm{Mg}^{2+}$. Para SB e CTC efetiva, as maiores concentrações foram obtidas a partir da dose $80 \mathrm{Mg} \mathrm{ha}^{-1}$. A partir da dose $40 \mathrm{Mg} \mathrm{ha}^{-1} \mathrm{de}$ biochar foram obtidos valores de saturação por bases superiores a 50\%, tendo como consequência condições que permitem o desenvolvimento da maioria das plantas nos solos ácidos do Cerrado brasileiro.

A aplicação do biochar também elevou a CTC total do solo. Esta é uma propriedade fundamental para solos extremamente intemperizados e ácidos como os que predominam no Cerrado brasileiro. Entre as diferentes doses, no entanto, apenas a aplicação de $100 \mathrm{Mg} \mathrm{ha}^{-1}$ aumentou a CTC total em relação às doses de 20 e $40 \mathrm{Mg} \mathrm{ha}^{-1}$, não havendo diferenças entre as demais doses. O efeito da pirólise sobre a CTC do biochar é variável conforme a matéria prima. Méndez et al. (2013) verificaram diminuição do valor dessa propriedade com o aumento da temperatura de pirólise. Outros estudos têm demonstrado aumento da CTC, quando o biochar é obtido por pirólise lenta (Jeffery et al., 2011; Shenbagavalli \& Mahimairaja, 2012; Jien \& Wang, 2013). No presente estudo, esse aumento da CTC total pode ser justificado pela forma indireta de obtenção dessa propriedade, que considera o aumento da concentração de cátions trocáveis como cálcio e magnésio.

Diversos trabalhos têm mostrado incrementos na fertilidade do solo com aplicações de biochar, de matérias primas variadas e em diferentes culturas (Jeffery et al., 2011; Liu et al., 2014; Smider \& Singh, 2014; Oram et al., 2014; Soinne et al., 2014; Tammeorg et al., 2014), e também decréscimos nas concentrações de alguns nutrientes, com $\mathrm{P}, \mathrm{Ca}, \mathrm{Mg}, \mathrm{K}$ e micronutrientes (Smider \& Singh, 2014). Esses dados mostram a variabilidade que existe na utilização do biochar, pois diversos fatores como tipo de matéria prima, tempo e temperatura de pirólise, manejo, cultura, podem influenciar na viabilidade de utilização desse produto na agricultura.

No caso específico do biochar de LE, os resultados demonstram que a sua utilização como condicionador e fornecedor de nutrientes é uma alternativa viável para o cultivo de plantas de ciclo curto como o rabanete.

Na tabela 6 são apresentadas as concentrações de nitrato e amônio no solo após a aplicação de biochar. 
Tabela 6. Teores de nitrato $\left(\mathrm{NO}_{3}{ }^{-}\right)$e amônio $\left(\mathrm{NH}_{4}{ }^{+}\right)$do solo em resposta à dose de biochar aplicada.

\begin{tabular}{crlrl}
\hline $\begin{array}{c}\text { Dose } \\
\left(\mathrm{Mg} \mathrm{ha}^{-1}\right)\end{array}$ & $\mathrm{NO}_{3}^{-}$ & & $\mathrm{NH}_{4}{ }^{+}$ & \\
\hline 0 & & & $\mathrm{mg} \mathrm{kg}^{-1}$ & \\
20 & 7,32 & $\mathrm{c}$ & 7,32 & $\mathrm{~b}$ \\
40 & 12,22 & $\mathrm{bc}$ & 8,54 & $\mathrm{~b}$ \\
60 & 13,20 & $\mathrm{bc}$ & 8,38 & $\mathrm{~b}$ \\
80 & 12,14 & $\mathrm{bc}$ & 14,84 & $\mathrm{a}$ \\
100 & 20,06 & $\mathrm{~b}$ & 20,03 & $\mathrm{a}$ \\
\hline
\end{tabular}

Médias seguidas por letras iguais na coluna não diferem entre si pelo teste de Tukey $(\mathrm{p}<0,05)$.

Houve incremento de nitrato no solo a partir da dose de $80 \mathrm{Mg} \mathrm{ha}^{-1}$ de biochar, sendo que o maior teor foi obtido com o fornecimento da dose mais elevada de biochar. A maior diferença para o nitrato foi verificada entre o controle e a maior dose (100 $\left.\mathrm{Mg} \mathrm{ha}^{-1}\right)$, cujos teores se elevaram de 7,32 (controle) para 41,91 mg dm $\mathrm{mg}^{-3}\left(100 \mathrm{Mg} \mathrm{ha}^{-1}\right)$, com incremento de 5,72 vezes.

Para as concentrações de amônio a partir da dose $60 \mathrm{Mg} \mathrm{ha}^{-1}$ há ganho de aproximadamente $100 \%$ nos teores quando comparado com a dose zero (controle), mostrando também que há um enriquecimento do solo em $\mathrm{N}$ disponível pela adição do biochar. Isso pode ser explicado devido à menor perda desse elemento no processo de pirólise com temperatura baixa $\left(300^{\circ} \mathrm{C}\right)$ e maior disponibilidade na matéria prima. Zhang et al (2012) com biochar de madeira observaram o mesmo comportamento no cultivo de arroz.

Estudos têm mostrado que o biochar pode fornecer e tornar disponíveis para solução do solo essas duas formas de N (nitrato e amônio) (Singh et al., 2010b; Knowles et al., 2011). O mecanismo que pode explicar esse efeito é o aumento da adsorção de amônio (Zhang et al., 2012), com redução da lixiviação e maior disponibilidade dessa espécie química no solo (Lehmann et al., 2003). Com o incremento do teor de $\mathrm{N}$ no solo em virtude da adição de biochar ao solo, há uma diminuição da relação C:N, fato importante para explicar a crescente disponibilidade de amônio no solo, como resultado do equilíbrio entre os processos de mineralização e imobilização de N. Esse processo também ajuda a explicar os teores de nitrato no solo, pois parte do amônio mineralizado sofre nitrificação, disponibilizando nitrato 
para solução (Schmidt et al., 2014; Rosa et al., 2014). O nitrato também pode ser adsorvido através de grupos funcionais presentes no biochar (Yao et al., 2012).

A exemplo de outros nutrientes, o comportamento de formas disponíveis de $\mathrm{N}$ é muito variável conforme a matéria prima e o processo de obtenção do biochar. Diferentemente dos resultados apresentados no presente trabalho, em outras pesquisas com biochars obtidos em elevadas temperaturas, a concentração de nitrato e amônio tem diminuído no solo com aplicação de biochar. Alguns motivos que explicam esse efeito negativo são perdas de $\mathrm{N}$ por volatilização durante a pirólise, imobilização microbiológica, absorção pelas plantas, perdas gasosas $\left(\mathrm{N}_{2}\right)$, adsorção devido ao aumento da porosidade do solo com biochar e recalcitrância do N presente no biochar (Shenbagavalli \& Mahimairaja, 2012; Schulz et al., 2013; Nelissen et al., 2014; Tammeorg et al., 2014). 


\section{Teores de nutrientes nas folhas de rabanete em resposta à dose de biochar}

O aumento da concentração de nutrientes e dos indicadores de fertilidade do solo tiveram como consequência a maior absorção de nutrientes pela planta de rabanete, com o aumento da dose de biochar (Tabela 7).

Tabela 7. Teores de nutrientes na folha de rabanete em resposta às doses de biochar de lodo de esgoto.

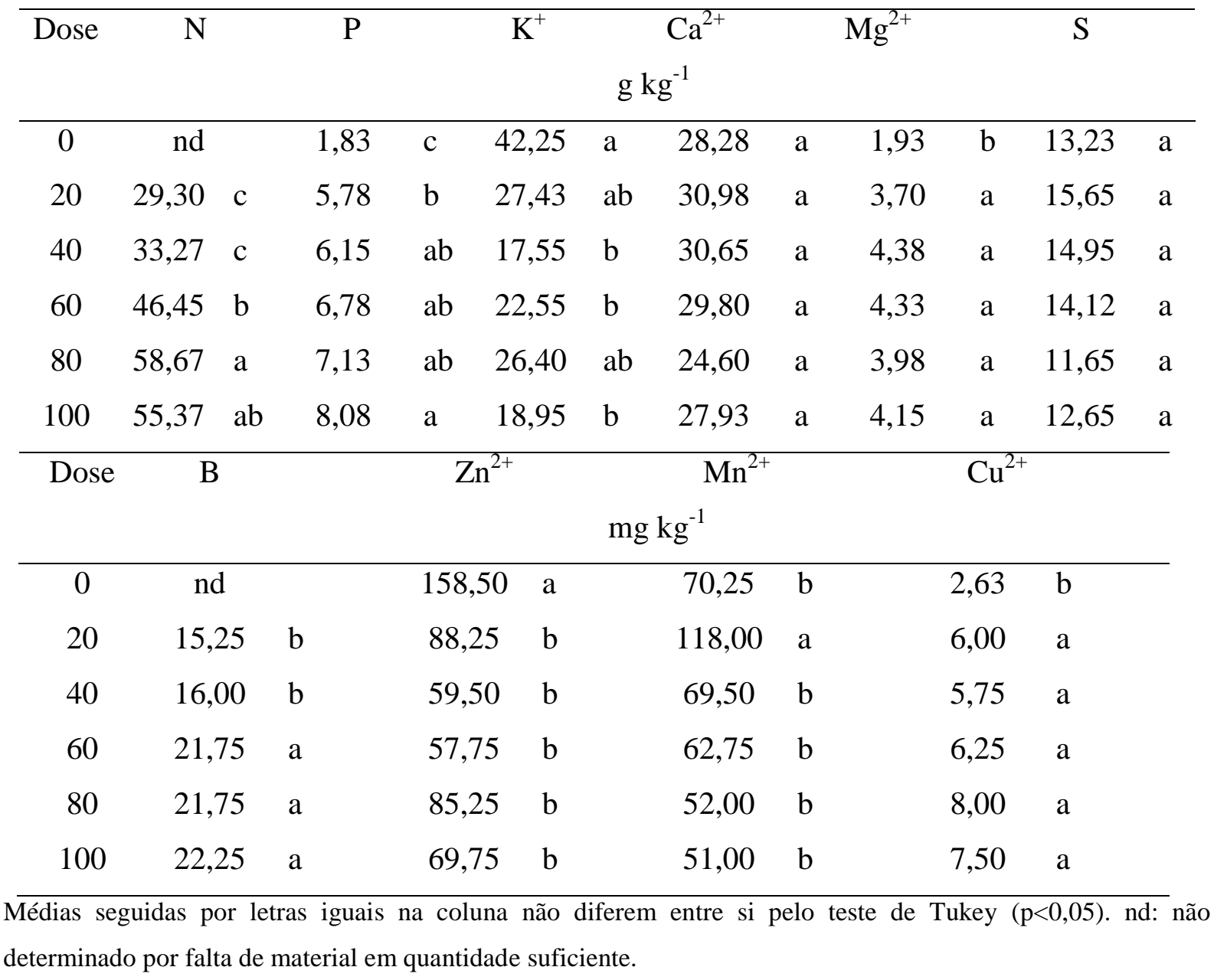

A concentração de nitrogênio na folha de rabanete aumentou proporcional a dose de biochar aplicada, sem incremento após a dose de $80 \mathrm{Mg} \mathrm{ha}^{-1}$. Para todas as doses os teores encontrados são considerados adequados para o rabanete (Boaretto et al., 2009). Essa maior absorção de $\mathrm{N}$ ocorreu devido aos elevados teores de $\mathrm{N}$ no biochar (Tabela 4) que se refletiu em aumento de $\mathrm{N}$ no solo em formas prontamente absorvíveis como $\mathrm{NO}_{3}{ }^{-} \mathrm{e}^{-} \mathrm{NH}_{4}{ }^{+}$(Tabela 6). Como consequência dessa maior absorção de N, o rabanete apresentou melhores indicadores 
de desenvolvimento (Figura 2). Chan et al. (2007) também mostraram maior absorção de N pelo rabanete quando aumentaram a dose de biochar aplicada ao solo. Possivelmente a absorção de amônio foi maior que a de nitrato, pois o $\mathrm{pH}$ do solo estava perto da neutralidade, o que favorece a absorção de $\mathrm{NH}_{4}{ }^{+}$(Cantarella, 2007).

$\mathrm{O}$ mesmo comportamento que ocorreu com o $\mathrm{N}$ foi observado nas concentrações de $\mathrm{P}$ nas folhas, que foram crescentes com o aumento da dose do biochar, chegando a ser três vezes maiores na dose $40 \mathrm{Mg} \mathrm{ha}^{-1}$ em comparação ao controle. Os elevados teores de $\mathrm{P}$ no solo (Tabela 5) proporcionado pelo biochar podem explicar os maiores teores desse nutriente nas plantas, considerados adequados no rabanete (Boaretto et al., 2009). Há também uma relação direta da absorção de $\mathrm{N}$ pela planta com a absorção do $\mathrm{P}$, pois adubações nitrogenadas influenciam de maneira positiva a absorção de P (Cantarella, 2007), o que pode ter ocorrido neste experimento. Além disso, o biochar tem melhorado o crescimento de micorrizas e com isso aumentado a absorção de P (Mau \& Utami, 2014; Hammer et al., 2014). Outro fator que pode explicar a maior absorção de $\mathrm{P}$ foi $\mathrm{o} \mathrm{pH}$ do solo próximo à neutralidade com reflexos positivos no aumento da disponibilidade desse nutriente no solo (Atkinson et al., 2010; Uzoma et al., 2011). No entanto, a aplicação de biochar em solos alcalinos pode ter efeito negativo na disponibilidade de $\mathrm{P}$ decorrente da sua precipitação com altos teores de sais (Smider \& Singh, 2014).

Ao contrário dos resultados encontrados para fósforo, não houve elevação dos teores de $\mathrm{K}$ na planta com a aplicação de biochar, chegando a haver redução nas concentrações em relação ao controle, nas doses de 40, 60 e $100 \mathrm{Mg} \mathrm{ha}^{-1}$, por efeito de diluição, uma vez que o controle produziu baixíssima quantidade de massa seca da parte aérea (Figura 3). Os baixos teores de K no rabanete com a aplicação de biochar pode ser resultado dos baixos teores fornecidos pelo biochar, do processo de lixiviação e de possíveis efeitos antagônicos com outros cátions, fornecidos em grandes quantidades pelo biochar como cálcio e amônio, que podem ter afetado a absorção de K pela planta (Ernani et al., 2007). Diferentemente dos resultados do presente estudo, as concentrações de $\mathrm{K}$ nas plantas aumentaram com a elevação da dose de biochar de madeira (Oram et al., 2014) e de resíduos verdes de tomate (Smider \& Singh, 2014), em virtude dos teores adequados desse nutriente na matéria prima.

De forma semelhante ao $\mathrm{P}$, o aumento da disponibilidade de $\mathrm{Mg}$ no solo pela adição de biochar (Tabela 5) se refletiu em maior acúmulo desse nutriente na planta de rabanete (Tabela 7). Os teores de $\mathrm{Mg}$ com a adição do biochar foram todos considerados adequados, enquanto o teor com a dose zero foi baixo (Boaretto et al., 2009). Apesar do teor de Mg no solo após o 
cultivo ter sido considerado baixo (Sousa \& Lobato, 2004), o rabanete conseguiu absorver o nutriente adequadamente, como resultado da adequada relação $\mathrm{Ca}: \mathrm{Mg}$, em torno de 5 (Gunes et al., 2014).

Os teores de cálcio e enxofre nas folhas de rabanete não foram alterados pela aplicação de biochar, apesar do aumento da disponibilidade de cálcio no solo promovido pelo biochar. Mecanismos de antagonismo podem ter impedido maior absorção de cálcio quando da aplicação de biochar. Apesar disso, os teores desses dois nutrientes foram considerados adequados para a cultura do rabanete (Boaretto et al., 2009).

A concentração de $\mathrm{B}$ nas folhas de rabanete aumentou a partir da dose $60 \mathrm{Mg} \mathrm{ha}^{-1}$ e sem diferenças para as demais doses superiores, mostrando que o biochar de LE também é uma fonte desse micronutriente tão importante para solos extremamente intemperizados como os que predominam no Cerrado brasileiro. A aplicação de biochar promoveu diminuição dos teores de $\mathrm{Zn}$ no rabanete. Apesar dessa diminuição, todos os teores encontrados foram considerados adequados (Boaretto et al., 2009). A elevada concentração de $\mathrm{Zn}$ no rabanete na dose zero (controle) pode ser resultado do fator diluição, como verificado para o potássio, promovido pela maior produção de massa seca da planta com a aplicação de biochar.

Assim como aconteceu com o $\mathrm{Mg}$, o teor de cobre nas folhas aumentou com adição do biochar, com aumentos superiores a $100 \%$ a partir da dose $20 \mathrm{Mg} \mathrm{ha}^{-1}$. Com a aplicação do biochar ao solo os teores nas folhas foram considerados adequados, entre 5 e $20 \mathrm{mg} \mathrm{kg} \mathrm{kg}^{-1}$ (Dechen \& Nachtigall, 2007). Com adição do biochar houve aumento na concentração de $\mathrm{Cu}$ nas folhas de forma inversa aos teores encontrados para Zn, que pode confirmar a relação de inibição da absorção entre esses dois nutrientes. Para Cu Smider \& Singh (2014) observaram que há um aumento na concentração desse nutriente nas folhas de milho em função da dose, efeito do fator concentração, devido ao baixo crescimento da planta.

O Mn teve seu maior teor para a dose $20 \mathrm{Mg} \mathrm{ha}^{-1}$, não havendo diferença entre as demais doses. Porém, todos os teores encontrados são considerados adequados, estando entre 50 e $250 \mathrm{mg} \mathrm{kg}^{-1}$ (Boaretto et al., 2009). Smider \& Singh (2014) observaram que a concentração desse nutriente na folha de milho não diminuiu em função da dose de biochar de resíduos verdes de tomate aplicada. 


\section{Parâmetros biométricos e produtividade do rabanete}

Como resultado da melhoria da fertilidade do solo e da maior absorção de nutrientes, a aplicação de biochar de LE promoveu aumento do desenvolvimento vegetativo da cultura do rabanete (Figura 3). Os indicadores de desenvolvimento da planta como número de folhas, comprimento de folhas, altura da planta e massa seca da parte aérea apresentaram resposta positiva a aplicação de biochar na faixa de 20 a $60 \mathrm{Mg} \mathrm{ha}^{-1}$ (Figura 3). Dessa forma, os resultados demonstram o potencial do biochar de LE para ser usado como fertilizante até em cultura de ciclo muito curto, como é o caso do rabanete. Esse potencial nutricional do biochar também foi observado por diversos pesquisadores com culturas e regiões diferentes, por exemplo, Chan et al. (2007) com biochar de LE na Austrália, Jha et al. (2010) com diversos biochars na Índia (rabanete), Hossain et al. (2010) com biochar de LE na Austrália (tomate), Zhang et al. (2012) com biochar de madeira, Khan et al. (2013) com biochar de LE na China (arroz), Liu et al. (2014) com biochar de LE na China (couve) e Smider \& Singh (2014) com biochar de madeira na Austrália (milho).

De maneira geral houve aumento nos parâmetros agronômicos avaliados em resposta à disponibilidade de nutrientes presentes no biochar. Chan et al. (2007) em estudo com rabanete com adição de biochar de LE observaram aumentos nesses parâmetros com doses a partir de $50 \mathrm{Mg} \mathrm{ha}^{-1}$, Hossain et al. (2011) com biochar de LE, Zhang et al. (2012) e Schulz et al. (2013) com biochar de madeira também verificaram comportamentos similares.

Smider \& Singh (2014) mostraram que a massa seca da cultura do milho foi aumentada em resposta a aplicação de biochar e Vaccari et al. (2011) verificaram aumento de $30 \%$ na biomassa do trigo com aplicação de $30 \mathrm{Mg} \mathrm{ha}^{-1}$ biochar de madeira. Já Tammeorg et al. (2014) não observaram melhorias na produção e nem na qualidade do grão de trigo com a aplicação de biochar de madeira.

O desenvolvimento da cultura durante a condução do experimento é apresentado na figura 2. A diferença no tamanho das plantas em função da dose a ser aplicada pode ser observada claramente, comprovando o efeito benéfico quando da utilização do biochar como adubo. 

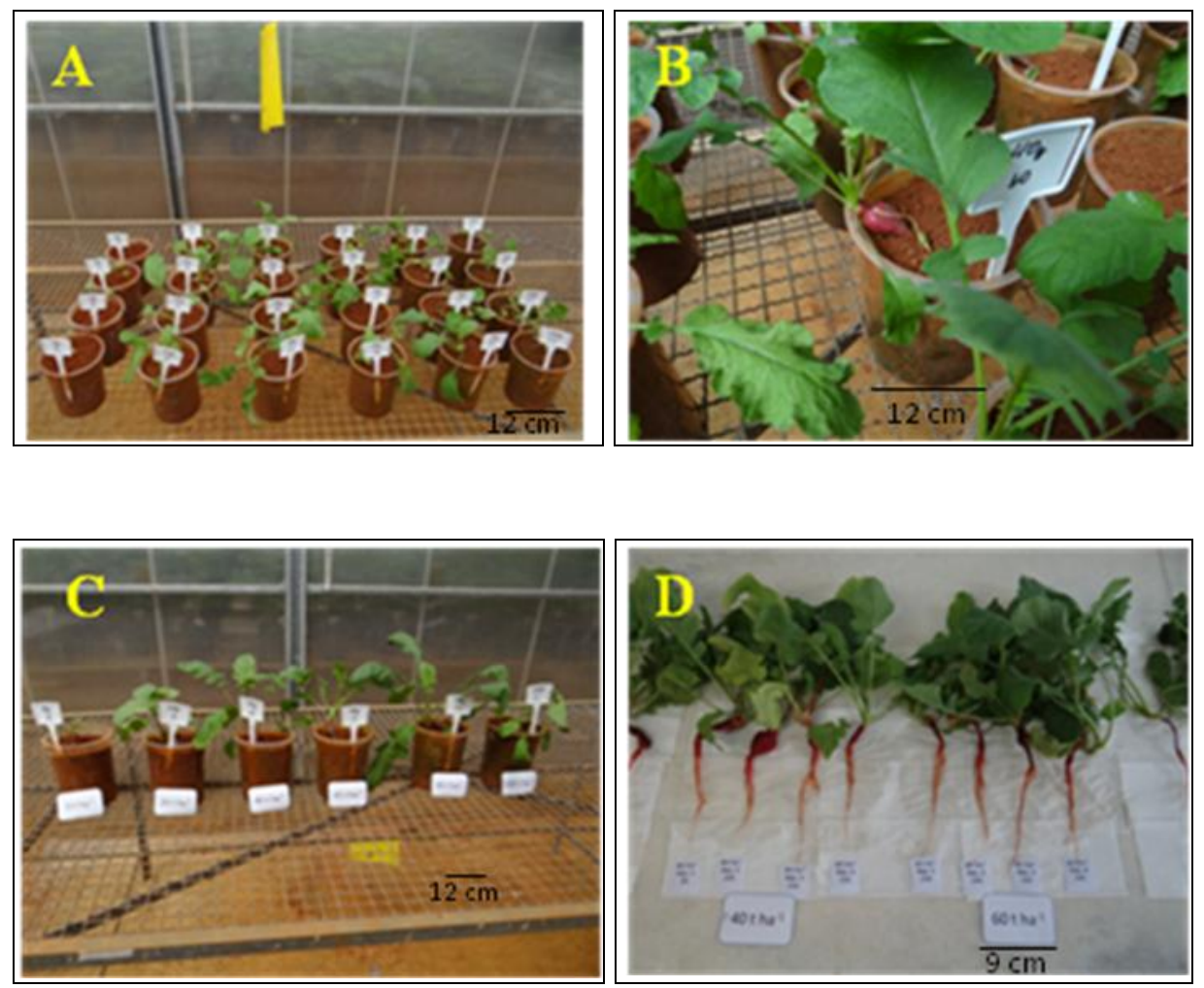

Figura 2. Desenvolvimento do rabanete em casa de vegetação. (A) plantas de rabanete sendo cultivada em vasos de $2 \mathrm{dm}^{3}$; (B) detalhes do vigor foliar da cultura; (C) aspectos do desenvolvimento da cultura em função da dose crescente de biochar, da esquerda para direita estão as doses 0 a $100 \mathrm{Mg} \mathrm{ha}^{-1}$; (D) detalhes do desenvolvimento do rabanete.

$\mathrm{Na}$ Figura 3 são apresentados os efeitos das doses de biochar nas características de desenvolvimento da planta. O comportamento da planta em função da dose de biochar foi representado pelo modelo quadrático para todas as características estudadas. 

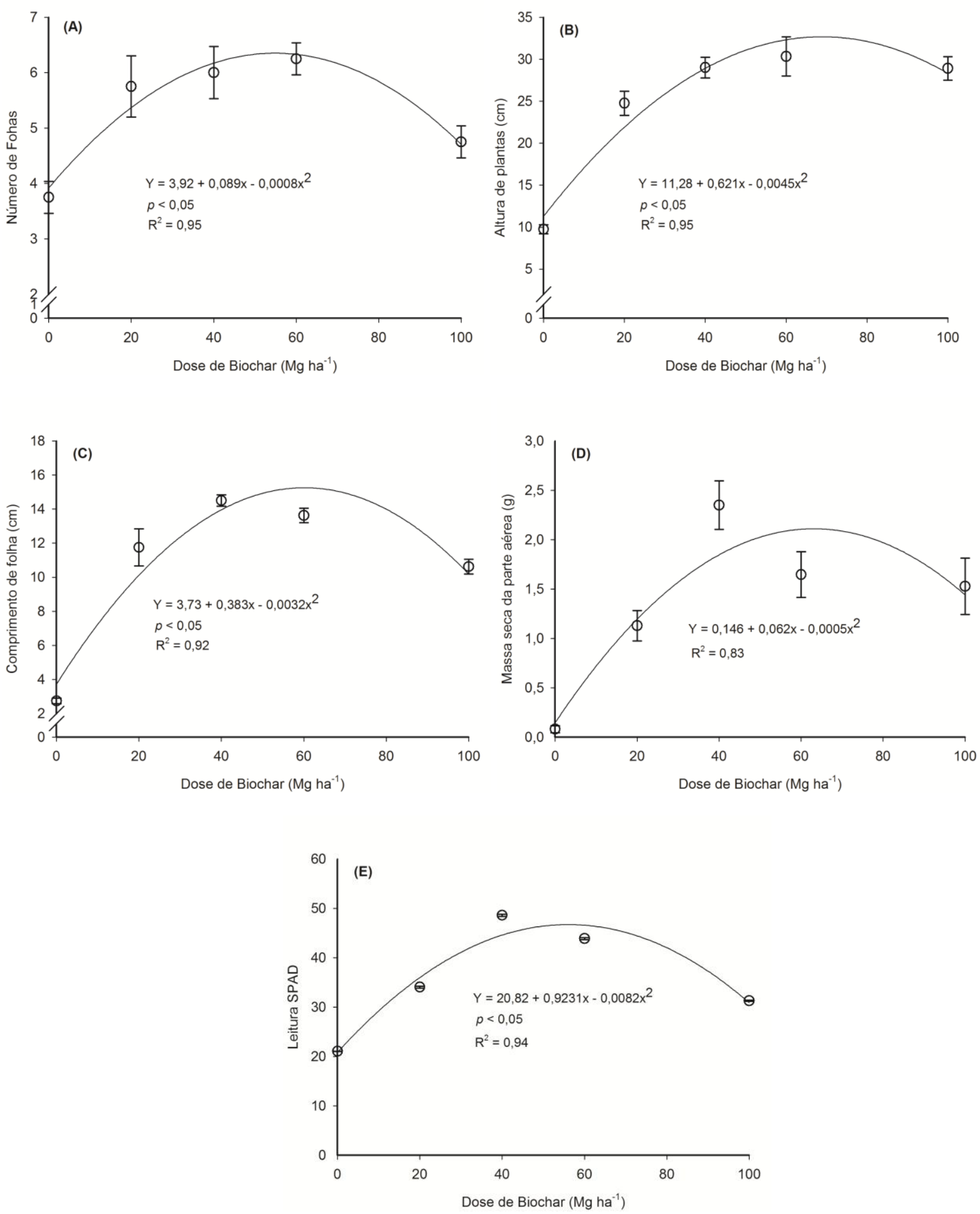

Figura 3. Efeito de doses de biochar de LE nos parâmetros biométricos da cultura do rabanete: (A) número de folhas; (B) altura das plantas; (C) comprimento das folhas; (D) massa seca da parte aérea; (E) teor de clorofila medida pelo índice SPAD. Barras verticais indicam o desvio padrão da média. 
$\mathrm{O}$ aumento da dose de biochar promoveu maior desenvolvimento da planta alcançando um ponto máximo, variando de 55 a $69 \mathrm{Mg} \mathrm{ha}^{-1}$, com consequente decréscimo nas doses mais elevadas. Isso pode ser resultado de possíveis desbalanços nutricionais como a limitação da disponibilidade de potássio e o excesso de outros nutrientes que limitam o desenvolvimento da planta em doses superiores. Outro fator que pode contribuir para esse efeito é a presença de 19,4 $\mathrm{g} \mathrm{kg}^{-1}$ de ácido húmico no biochar. Atiyeh et al. (2002) observaram decréscimos em altura de planta, área foliar e massa seca da raiz em tomate e pepino quando aplicaram mais de $0,5 \mathrm{~g} \mathrm{~kg}^{-1}$ de ácido húmico.

Quanto ao número de folhas verificou-se uma dose ideal de $55,6 \mathrm{Mg} \mathrm{ha}^{-1}$ com produção de 6,4 folhas por planta (Figura 3A). Pereira et al. (2011), utilizando húmus de minhoca e esterco bovino como adubo orgânico, encontraram 7,4 e 5,6 folhas por planta de rabanete, respectivamente. Para altura de plantas, a melhor dose ficou em $69 \mathrm{Mg} \mathrm{ha}^{-1}$, com altura de $32,7 \mathrm{~cm}$ (Figura 3B). No mesmo estudo de Pereira et al. (2011) a altura do rabanete foi 4,1 e 2 $\mathrm{cm}$ para húmus de minhoca e esterco bovino, respectivamente.

O comprimento de folha foi máximo com a dose de 59,8 $\mathrm{Mg} \mathrm{ha}^{-1}$, obtendo-se 15,2 $\mathrm{cm}$ de comprimento (Figura 3C), dose similar a encontrada para o número de folhas.

Quanto ao índice SPAD, a dose que possibilitou a produtividade máxima foi de $56,2 \mathrm{Mg}$ $\mathrm{ha}^{-1}$, e ficou semelhante a encontrada para comprimento e número de folhas, tendo como resultado 46,8 unidades SPAD (Figura 3E). O SPAD faz a leitura através de dois emissores de luz (luz vermelha e infravermelha) e corresponde ao teor de pigmento presente na folha (Malavolta et al., 1997). Essa medida correlaciona-se positivamente com o teor de clorofila nas folhas e com o rendimento da cultura. De 50 a $70 \%$ do $\mathrm{N}$ presente nas folhas fazem parte de enzimas que estão associadas aos cloroplastos, que podem refletir o teor de nitrogênio nas folhas medido através do SPAD (Reinbothe et al., 2010; Singh et al., 2010b). Malavolta et al. (1997) mostraram que para algumas culturas a unidade SPAD adequada varia de 40 a 56, como exemplo do arroz (>40), batatinha (49-56), milho (45-48). Diferente dos resultados obtidos no presente trabalho, em trabalho realizado com espinafre, as leituras SPAD realizadas por Milla et al. (2013) foram decrescentes com aplicação de biochar de madeira e casca de arroz, resultado justificado pelos baixos teores de nitrogênio presentes nesses biochars (Milla et al., 2013). Isso mostra a importância de se utilizar matérias primas ricas em nitrogênio, como é o caso do LE utilizado nesse trabalho.

A dose que possibilitou a máxima produção de massa seca da parte aérea foi $62 \mathrm{Mg} \mathrm{ha}^{-1}$, com peso de 2,1 g/planta (Figura 3D). Resultados semelhantes foram obtidos por outros 
autores com biochar ou outros adubos orgânicos, demonstrando o potencial nutricional do biochar de LE para a produção de culturas agrícolas de ciclo curto. Chan et al. (2007) obtiveram produção de massa seca da parte aérea de rabanete com dose de 50 e $100 \mathrm{Mg} \mathrm{ha}^{-1}$ de biochar de resíduos verdes, de 1,0 e 1,2 g/planta, respectivamente. Quando aplicaram biochar combinado com adubação nitrogenada (100 $\left.\mathrm{kg} \mathrm{N} \mathrm{ha}^{-1}\right)$ para essas mesmas doses, os resultados foram 3,7 e 4,5 g/planta. Pereira et al (2011) utilizando outras fontes de adubo orgânico (húmus de minhoca e esterco bovino) no cultivo de rabanete produziram 1,5 e 0,5 g/planta de massa seca da parte aérea, respectivamente. Vitti et al. (2007) utilizaram vermicomposto bovino com doses de 5, 20, 30 e $50 \mathrm{~g}$ por planta de rabanete e produziram massa seca aérea de 1,96, 1,88,2,26 e 2,58 g/planta, respectivamente, mostrando que os resultados encontrados no presente trabalhos estão coerentes e similares aos encontrados por outros autores.

Os efeitos do biochar no desempenho vegetativo da cultura de rabanete foram positivos para todas as características biométricos estudados (Figura 3). Esse adequado desenvolvimento da planta é decorrente das características agronômicas do biochar de LE, que além de aumentar a disponibilidade de macro e micronutrientes, melhorando o desenvolvimento das plantas, pode reduzir a lixiviação desses nutrientes (Uzoma et al., 2011; Gunes et al., 2014). Essa resposta da planta ao biochar também foi verificada em diversos trabalhos com diferentes biochars e culturas: com aveia e biochar de madeira (Schulz et al., 2013); em espinafre com biochar de casca de arroz e madeira (Milla et al., 2013); em tomate com biochar de LE (Khan et al., 2013) e na cultura do milho com biochar de madeira (Smider $\&$ Singh, 2014). Este bom desenvolvimento vegetativo do rabanete é importante para avaliar a resposta da planta ao biochar como fertilizante, como resultado da capacidade da planta realizar fotossíntese e se desenvolver, com reflexos no rendimento da cultura (Uzoma et al., 2011).

Como resultado dos benefícios no solo e na planta, o biochar aumentou a produtividade de tubérculo do rabanete (Figura 4). A dose de $20 \mathrm{Mg} \mathrm{ha}^{-1}$ promoveu a maior produtividade do rabanete, não diferindo apenas da dose de $40 \mathrm{Mg} \mathrm{ha}^{-1}$. A partir desta dose não houve incremento significativo na produtividade de tubérculos. A produtividade encontrada no presente trabalho com o uso de biochar de LE está próxima a encontrada quando se utiliza outros tipos de resíduos orgânicos. Costa et al. (2006), por exemplo, utilizando húmus de minhoca e esterco bovino em doses de 15,30 e $45 \mathrm{Mg} \mathrm{ha}^{-1}$, colheram respectivamente $1.120 \mathrm{e}$ $1.570 \mathrm{~kg} \mathrm{ha}^{-1}$ de rabanete comercial. No entanto, essas produtividades (15.000 a $30.000 \mathrm{~kg} \mathrm{ha}$ 
1) ainda são consideradas baixas, quando comparadas com as produtividades em sistema convencional de cultivo. Esse baixo rendimento talvez seja efeito do vaso, que pode ter limitado a expansão das raízes e/ou a redução de radiação solar sobre os rabanetes em casa de vegetação, que também pode ter contribuído para o decréscimo do tamanho e peso dos tubérculos (Souza et al., 1999).

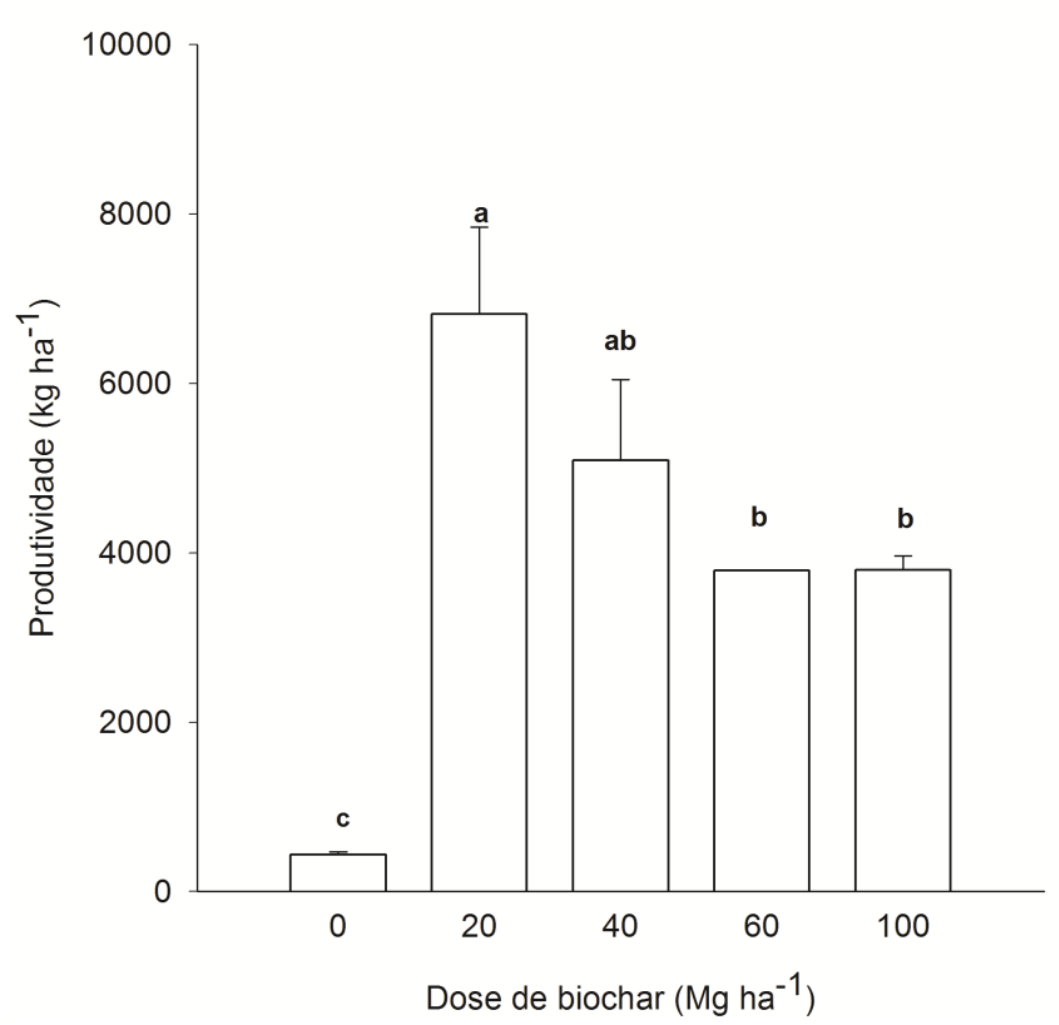

Figura 4. Produtividade estimada do rabanete em resposta à dose de biochar de lodo de esgoto.

Todos esses resultados são respostas das melhorias que ocorreram com a aplicação de biochar ao solo. Melhorias nas propriedades químicas, físicas e biológicas do solo (Chan et al., 2007; Hossain et al., 2011; Rosa et al., 2014). Esse bom desempenho agronômico apresentado pela cultura do rabanete com adição de biochar de LE como adubo é resultado dos altos teores de nutrientes essenciais para plantas, como fósforo, nitrogênio e micronutrientes, como já demonstrando anteriormente. 


\subsection{CONCLUSÕES}

1. Houve um enriquecimento dos nutrientes no solo com a aplicação do biochar de LE, principalmente fósforo, nitrogênio disponível, cátions trocáveis (cálcio e magnésio). $\mathrm{O}$ biochar também elevou os indicadores de fertilidade do solo como soma de bases e saturação por bases e a capacidade de troca catiônica e não apresentou efeito sobre os componentes da acidez do solo.

2. O aumento dos teores de nutrientes, promovidos pelo biochar, se refletiu em maior concentração de nutrientes foliares, com exceção para potássio, zinco e magnésio, promovendo um maior desenvolvimento da planta.

3. O biochar promoveu maior desenvolvimento da planta com aumento nos valores de altura de plantas, massa seca da parte aérea, número de folhas, comprimento de folha e leitura SPAD.

4. Considerando todas as variáveis testadas, a resposta da planta a aplicação do biochar alcançou os maiores valores com as doses entre 20 e $60 \mathrm{Mg} \mathrm{ha}^{-1}$, sendo observada uma leve redução a partir da dose $60 \mathrm{Mg} \mathrm{ha}^{-1}$.

5. De maneira geral o biochar foi capaz de fornecer nutrientes às plantas em curto período, tendo como consequência o aumento da produtividade do rabanete, representando uma alternativa viável para o uso agrícola do LE do ponto de vista da produção. 


\subsection{CONSIDERAÇÕES FINAIS}

Neste trabalho foi demonstrada a viabilidade agronômica na utilização do biochar de LE como fertilizante para culturas de ciclo curto, como o rabanete. Os resultados obtidos foram importantes do ponto de vista da pesquisa agrícola e apresentaram melhorias nas características químicas do solo proporcionadas pelo uso de biochar de LE.

Sugere-se que sejam realizadas mais pesquisas referentes à aplicabilidade do biochar de LE na agricultura em nível de campo e também quanto à viabilidade operacional e econômico-financeira para esse fim. Além de determinar a quantidade de metais tóxicos presente no biochar em atendimento a resolução CONAMA 375 de 2006 e outras pesquisas no âmbito da fertilidade do solo. 


\subsection{REFERÊNCIAS BIBLIOGRÁFICAS}

ADDINSOFT 'XLSTAT 2013: statistical sofware to MS Excel.' Addinsoft: New York, 2013.

ATIYEH, R. M.; LEE, S.; EDWARDS, C. A.; ARANCON, N. Q.; METZGER, J. D. The influence of humic acids derived from earthworm-processed organic wastes on plant growth. Bioresource Technology, 84: 7-14, 2002.

ATKINSON, C. J.; FITZGERALD, J. D.; HIPPIS, N. A. Potential mechanisms for achieving agricultural benefits from biochar application to temperate soils: a review. Plant and Soil, $337: 1-18,2010$.

BEESLEY, L.; MARMIROLI, M. The immobilisation and retention of soluble arsenic, cadmium and zinc by biochar. Environmental Pollution, 159: 474-480, 2011.

BIEDERMAN, L. A.; HARPOLE, W. S. Biochar and its effects on plant productivity and nutrient cycling: a meta-analysis. Global Change Biology Bioenergy, 5: 202-214, 2013.

BOARETTO, A. E.; RAIJ, B. V.; SILVA, F. C.; CHITOLINA, J. C.; TEDESCO, M. J.; CARMO, C. A. F. S. Amostragem, acondicionamento e preparo de amostras de plantas para análise química. In: Manual de análises químicas de solos, plantas e fertilizantes. 2 ed. ver. ampl. Brasília, DF: Embrapa Informação Tecnológica, 2009. 627p.

CAESB. Companhia de Saneamento Ambiental do Distrito Federal. Disponível em: http://www.caesb.df.gov.br/esgoto/sistemas-de-esgotamento.html. Acesso em: 30 de junho de 2014.

CANTARELLA, H. Nitrogênio. In: Fertilidade do solo. Viçosa, MG. Sociedade Brasileira de Ciência do Solo, 2007. 1017p. 
CARDOSO, A. I. I.; HIRAKI, H. Avaliação de doses e épocas de aplicação de nitrato de cálcio em cobertura na cultura do rabanete. Horticultura Brasileira, Brasília, 19: 328-331, 2001.

CHAN, K. Y.; VAN ZWIETEN, L.; MESZAROS, I.; DOWNIE, A.; JOSEPH, S. Agronomic values of greenwaste biochar as a soil amendment. Australian Journal of Soil Research, 45: 629-634, 2007.

CHINTALA, R.; SCHUMACHER, T. E.; McDONALD, L. M.; CLAY, D. E.; PAPIERNIK, S. K.; CLAY, S. A.; JULSON, J. L. Phosphorus sorption and availability from biochars and soil/biochar mixtures. Clean - Soil, Air, Water, 42: 626-634, 2014.

CHITOLINA, J. C.; PRATA, F.; SILVA, F. C.; COELHO, A. M.; CASARINI, D. C. P.; MUROAKA, T.; VITTI, A. C.; BOARETTO, A. E. Amostragem de solo para análises de fertilidade, de manejo e de contaminação. In: Manual de análises químicas de solos, plantas e fertilizantes. 2. Ed. revisada e ampliada. Brasília, DF: Embrapa Informação Tecnológica, 2009.

COSTA, C. C.; OLIVEIRA, C. D.; SILVA, C. J.; TIMOSSI, P. C.; LEITE, I. C. Crescimento, produtividade e qualidade de raízes de rabanete cultivadas sob diferentes fontes e doses de adubos orgânicos. Horticultura Brasileira, 24: 118-122, 2006.

DECHEN, A. R.; NACHTIGALL, G. R. Elementos requeridos à nutrição de plantas. In: Fertilidade do solo. Viçosa, MG. Sociedade Brasileira de Ciência do Solo, 2007. 1017p.

EMBRAPA. Centro Nacional de Pesquisa de Solos. Manual de métodos de análise de solos. 2 ed. Rio de Janeiro, 1997. 212p.

ERNANI, P. R.; ALMEIDA, J. A.; SANTOS, F. C. Potássio. In: Fertilidade do solo. Viçosa, MG. Sociedade Brasileira de Ciência do Solo, 2007. 1017p.

FAQUIN, V. Nutrição mineral de plantas. Lavras: UFLA/FAEPE, 2005. 183p. 
FISCHER, D.; GLASER, B. Synergisms between compost and biochar for sustainable soil amelioration In: Management of Organic Waste. Institute of Agricultural and Nutritional Sciences, Soil Biogechemistry, Halle. Germany, 2012. 198p.

FREE, H. F.; McGILL, C. R.; ROWARTH, J. S.; HEDLEY, M. J. The effect of biochars on maize (Zea mays) germination. New Zealand Journal of Agriculture Research, 53: 1-4, 2010.

GASKIN, J. W.; STEINER, C.; HARRIS, K.; DAS, K. C.; BIBENS, B. Effect of low-temperature pyrolysis conditions on biochar for agricultural use. Transaction of the Asabe, 51: 2061-2069, 2008.

GUNES, A.; INAL, A.; TASKIN, M. B.; SAHIN, O.; KAYA, E. C.; ATAKOL, A. Effect of phosphorus-enriched biochar and poultry manure on growth and mineral composition of lettuce (Lactuca sativa L. cv.) grown in alkaline soil. Soil Use and Management, 30: 182$188,2014$.

HAMMER, E. C.; BALOGH-BRUNSTAD, Z.; JAKOBSEN, I.; OLSSON, P. A.; STIPP, S. L. S.; RILLIG, M. C. A mycorrhizal fungus grows on biochar and captures phosphorus from its surfaces. Soil Biology \& Biochemistry, 77: 252-260, 2014.

HERATH, H. M. S. K.; CAMPS-ARBESTAIN, M.; HEDLEY, M. Effects of biochar on soil physical properties in two contrasting soils: an alfisol and andisol. Geoderma, 209-210: 188197, 2013.

HOSSAIN, M. K.; STREZOV, V.; CHAN, K. Y.; ZIOLKOWSKI, A.; NELSON, P. F. Influence of pyrolysis temperature on production and nutrient properties of wastewater sludge biochar. Journal of Environmental Management, 92: 233-228, 2011.

HOSSAIN, M. K.; STREZOV, V.; CHAN, K. Y.; NELSON, P. F. Agronomic properties of wastewater sludge biochar and bioavailability of metals in production of cherry tomato (Lycopersicon esculentum). Chemosphere, 78: 1167-1171, 2010. 
INTERNATIONAL BIOCHAR INITIATIVE. Standardized product definition and product testing guidelines for biochar that is used in soil. 2012. Available at: <http://www.biocharinternational.org/sites/default/files/Guidelines_for_Biochar_That_Is_Used_in_Soil_Final .pdf>. Acesso em: 12 de novembro de 2013.

JHA, P.; BISWAS, A. K.; LAKARIA, B. L.; SUBBA RAO, A. Biochar in agriculture prospects and related implications. Current Science, 99: 1218-1225, 2010.

JEFFERY, L. S.; VERHEIJEN, F. G. A.; VAN DER VELDE, M.; BASTOS, A. C. A quantitative review of the effects of biochar application to soils on crop productivity using meta-analysis. Agriculture, Ecosystems and Environmen, 144: 175-187, 2011.

JIEN, S.; WANG, C. Effects of biochar on soil properties and erosion potential in a highly weathered soil. Catena, 110: 225-233, 2013.

JUNIO, G. R. Z.; SAMPAIO, R. A.; NASCIMENTO, A. L.; SANTOS, G. B.; SANTOS, L. D. T.; FERNANDES, L. A. Produtividade de milho com composto de lodo de esgoto e fosfato natural de Gafsa. Revista Brasileira de Engenharia Agrícola e Ambiental, 17:706$712,2013$.

KHAN, S.; CHAO, C.; WAQAS, M.; ARP, H. P. H.; ZHU, Y. Sewage sludge biochar influence upon rice (Oryza sativa L) yield, metal bioaccumulation and greenhouse gas emissions from acidic paddy soil. Environmental Science \& Technology, 47: 8624-8632, 2013.

KNOWleS, O. A. O.; ROBINSON, B. H. B.; CONTANGElO, A. A.; CluCAS, L. L. Biochar for the mitigation of nitrate leaching from soil amended with biosolids. The Science of the Total Environment, 409: 3206-3210, 2011.

LEHMANN, J. SILVA JUNIOR, J. P.; STEINER, C.; NEHLS, T.; ZECH, W.; GLASER, B. Nutrient availability and leaching in an archaeological Anthrosol and a Ferralsol of the Central Amazon basin: fertilizer, manure and charcoal amendments. Plant and Soil, 249: 343-357, 2003. 
LIU, T.; LIU, B.; ZHANG, W. Nutrients and heavy metals in biochar produced by sewage sludge pyrolysis: Its application in soil amendment. Polish Journal of Environmental Studies, 23: 271-275, 2014.

MALAVOlTA, E.; VITTI, G. C.; OLIVEIRA, S. A. de. Avaliação do estado nutricional das plantas: princípios e aplicações. Piracidaca: Associação Brasileira para Pesquisa da Potassa e do Fosfato, 1989. 201p.

MAU, A. E.; UTAMI, S. R. Effects of biochar amendment and arbuscular mycorrhizal fungi inoculation on availability of soil phosphorus and growth of maize. Journal of Degraded and Mining Lands Management, 1:69-74, 2014.

MÉNDEZ, A.; TARQUIS, A. M.; SAA-REQUEJO, A.; GUERRERO, F.; GASCO, G. Influence of pyrolysis temperature on composted sewage sludge biochar priming effect in a loamy soil. Chemosphere, 93: 668-676, 2013.

MILLA, O. V.; RIVERA, E. B.; HUANG, W. J.; CHIEN, C. C.; WANG, Y. M. Agronomic properties and characterization of rice husck and wood biochars and their effect on the growth of water spinach in a field test. Journal of Soil Science and Plant Nutrition, 13: 251-266, 2013.

NASCIMENTO, C. W. A.; BARROS, D. A. S.; MELO, E. E. C.; OLIVEIRA, A. B. Alterações químicas em solos e crescimento de milho e feijoeiro após aplicação de lodo de esgoto. Revista Brasileira de Ciência do Solo, 28:385-392, 2004.

NELISSEN, V.; RUYSSCHAERT, G.; MULLER-STOVER, D.; BODE，S.; COOK, J.; RONSSE, F.; SHACKLEY, S.; BOECKX, P.; HAUGGAARD-NIELSEN, H. Short-term effect of feedstock and pyrolysis temperature on biochar characteristics, soil and crop response in temperate soils. Agronomy, 4: 52-73, 2014.

NETO, A. E. F.; VALE, F. R.; RESENDE, A. V.; GUILHERME, L. R. G.; GUEDES, G. A. A. Fertilidade do solo. Lavras: UFLA/FAEPE, 2001. 252p. 
ORAM, N. J.; VOORDE, T. F. J. V.; OUWEHAND, G. J.; BEZEMER, T. M.; MOMMER, L.; JEFFERY, S.; GROENIGEN, J. W. V. Soil amendment with biochar increases the competitive ability of legumes via increased potassium availability. Agriculture, Ecosystems and Environment, 191: 92-98, 2014.

PARK, J. H.; CHOPPALA, G. K.; BOLAN, N. S.; CHUNG, J. W.; CHUASAVATHI, T. Biochar reduces the bioavailability and phytotoxicity of heavy metals. Plant and Soil, 348: 439-451, 2011.

PEREIRA, K .S.; SANTOS, C. H. B.; NASCIMENTO, W. A.; ARMOND, C.; SILVA, F.; CASA, J. Crescimento de rabanete (Raphanus sativus L.) em resposta a adubação orgânica e biofertilizantes em ambiente protegido. Horticultura Brasileira, 29: 4414-4420, 2011.

PRAKONGKEP, N.; GILKES, R. J.; WIRIYAKITNATEEKUL, W. Agronomic benefits of durian shell biochar. Journal of Metals, Materials and Minerals, 24: 7-11, 2014.

REINBOTHE, C.; BAKKOURI, M.; BUHR, F.; MURAKI, N.; NOMATA, J.; KURISU, G.; FUJITA, Y.; REINBOTHE, S. Chlorophyll biosynthesis: spotlight on protochlorophyllide reduction. Trends in Plant Science, 15: 614-624, 2010.

ROSA, J. M. L.; PANEQUE, M.; MILLER, A. Z.; KNICKER, H. Relating physical and chemical properties of four different biochars and their application rate to biomass production of Lolium perenneon a Calcic Cambisol during a pot experiment of 79 days. Science of the Total Environment, 499:175-184, 2014.

SCHMIDT, H.; KAMMANN, C.; NIGGLI, C.; EVANGELOU, M. W. H.; MACKIE, K. A.; ABIVEN, S. Biochar and biochar-compost as soil amendments to a vineyard soil: influences on plant growth, nutrient uptake, plant health and grape. Agriculture, Ecosystems and Environment, 191: 117-123, 2014.

SCHULZ, H.; DUNST, G.; GLASER, B. Positive effects of composted biochar on plant growth and soil fertility. Agronomy for Sustainable Development, 33: 817-827, 2013. 
SHENBAGAVALLI, S.; MAHIMAIRAJA, S. Characterization and effect of biochar on nitrogen and carbon dynamics in soil. International Journal of Advanced Biological Research, 2: 249-255, 2012.

SINGH, B.; SINGH, B. P.; COWIE, A. L. Characterisation and evaluation of biochars for their application as a soil amendment. Soil Research, 48: 516-525, $2010 \mathrm{a}$.

SINGH, V.; SINGH, B.; SINGH, Y.; THIND, H. S.; GUPTA, R. K. Need based nitrogen management using the chlorophyll meter and leaf colour chart in rice and wheat in South Asia: a review. Nutrient Cycling Agroecosyst, 88: 361-380, $2010 \mathrm{~b}$.

SMIDER, B.; SINGH, B. Agronomic performance of a high ash biochar in two contrasting soils. Agriculture, Ecosystems and Environment, 191: 99-107, 2014.

SOINNE, H.; HOVI, J.; TAMMEORG, P.; TURTOLA, E. Effect of biochar on phosphorus sortion and clay soil aggregate stability. Geoderma, 219-220: 162-167, 2014.

SOUSA, D. M. G.; LOBATO, E. Cerrado: correção do solo e adubação. 2. ed. Brasília, DF: Embrapa Informação Tecnológica, 2004. 416p.

SOUZA, J. R. P.; MEHL, H. O.; RODRIGUES, J. D.; PEDRAS, J. F. Sombreamento e o desenvolvimento e produção de rabanete. Scientia Agrícola, 56: 987-992, 1999.

SPOKAS, K. A.; CANTRELL, K. B.; NOVAK, J. M.; ARCHER, D. W.; I, J. A.; COLLINS, H. P.; BOATENG, A. A.; LIMA, I. M.; LAMB, M. C.; MCALOON, A. J.; LENTZ, R. D.; NICHOLS, K. A. Biochar: A synthesis of its agronomic impact beyond carbon sequestration. Journal of Environmental Quality, special section: 973-989, 2012.

TAMMEORG, P.; SIMOJOKI, A.; MAKELA, P.; STODDARD, F. L.; ALAKUKKU, L.; HELENIUS, J. Short-term effects of biochar on soil properties and wheat yield formation with meat bone meal inorganic fertilizer on a boreal loamy sand. Agriculture, Ecosystems and Environment, 191: 108-116, 2014. 
UZOMA, K, C.; INOUE, M.; ANDRY, H.; FUIJIMAKI, H.; ZAHOOR, A.; NISHIHARA, E. Effect of cow manure biochar on maize productivity under sandy soil condition. Soil Use and Management, 27: 205-212, 2011.

VACCARI, F. P.; BARONTI, E. L.; GENESIO, L.; CASTALDI, S.; FORNASIER, F.; MIGLIETTA, F. Biochar as a strategy to sequester carbon and increase yield in durum wheat. European Journal of Agronomy, 34: 231-238, 2011.

VITTI, M. R.; VIDAL, M. B.; GAMBOA, T. B.; MORSELLI, A.; FARIA, J. L. C. Resposta do rabanete a adubação orgânica em ambiente protegido. Revista Brasileira de Agroecologia, v: 1158-1161, 2007.

YAO, Y.; GAO, B.; ZHANG, M.; INYANG, M.; ZIMMERMAN, A. R. Effect of biochar amendment on sorption and leaching of nitrate, ammonium, and phosphate in sandy soil. Chemosphere, 89: 1467-1471, 2012.

YUAN, J. H.; XU, R. K.; ZHANG, H. The forms of alkalis in the biochar produced from crop residues at different temperatures. Bioresource Technology, 102: 3488-3497, 2011.

YUAN, H.; LU, T.; ZHAO, D.; HUANG, H.; NORIYUKI, K.; CHEN, Y. Influence of temperature on product distribution and biochar properties by municipal sludge pyrolysis. Journal Material Cycles Waste Management, 15: 375-361, 2013.

ZHANG, A.; BIAN, R.; PAN, G.; CUI, L.; HUSSAIN, Q.; LI, L.; ZHENG, J.; ZHANG, X.; HAN. X.; YU, X. Effects of biochar amendment on soil quality, crop yield and greenhouse gas emission in a Chinese rice paddy: A field study of 2 consecutive rice growing cycles. Field Crops Research, 127: 153-160, 2012. 